\title{
Release Behavior of Bovine Serum Albumin Loaded on Hydrogels of Natural Polymer Blend Poly (Vinyl Alcohol) and Analyze Their Compositions
}

\author{
Roua'a Kassim Al-Ojar', Fawzi Habeeb Jabrail, " \\ ${ }^{1}$ Ministry of Science and Technology, Mosul, Iraq \\ ${ }^{2}$ Department of Chemistry, College of Science, University of Mosul, Mosul, Iraq
}

Email address:

fawzidcy@yahoo.com (F. H. Jabrail)

*Corresponding author

To cite this article:

Roua'a Kassim Al-Ojar, Fawzi Habeeb Jabrail. Release Behavior of Bovine Serum Albumin Loaded on Hydrogels of Natural Polymer Blend Poly (Vinyl Alcohol) and Analyze Their Compositions. American Journal of Polymer Science and Technology.

Vol. 5, No. 2, 2019, pp. 40-54. doi: 10.11648/j.ajpst.20190502.12

Received: March 16, 2019; Accepted: April 26, 2019; Published: June 4, 2019

\begin{abstract}
Amylopectin AP, shellac SH, starch ST and ethyl cellulose EC, the natural polymers of multi functional groups have been blended with poly (vinyl alcohol). The new hydrogels were cross-linked chemically and physically using glutaraldehyde and sodium hexametaphosphate respectively. The prepared hydrogels and according to their different functional groups were studied for their degree of swelling in (pH4, $\mathrm{pH} 7$ and $\mathrm{pH} 9$ ) swelling medium and in saline solution of $0.1 \mathrm{~N} \mathrm{NaCl}$. The $\mathrm{wt} \%$ of blend composite of the final hydrogels beside their degree of cross-link was manipulated for maximum loading and suitable release of BSA protein. FT-IR studies were used to improve blending of the mixed polymers in prepared hydrogels from their distinctive functional groups in the final hydrogels structures, as well as the emphasis on BSA protein loaded on prepared hydrogel. The XRD patterns have shown low crystalline structure of the prepared hydrogels after blending, with some elevation in degree of crystallinity for hydrogels cross-linked physically in comparison with hydrogels chemically cross-linked. The DTA thermograms have shown blending of polymers would change the thermal stability of the final hydrogels, and according to their $\mathrm{Tg}$, Tcr and $\Delta \mathrm{H}_{\mathrm{f}}$ the hydrogels were thermally more stable in chemically cross-linked structures than cross-linked physically which because of their ionic interactions and their competition with hydrogen bonds. SEM micrographs have shown the homogeneous structures of the hydrogels after blending beside the irregular and fold surface for chemical cross-linked hydrogels which increase the surface area and increase the loading efficiency of some prepared hydrogels. Whereas physical cross-linked hydrogels have shown surface of smooth and uniform character with high porosity which increase the loading percentage too. The BSA protein model was depended for loading on prepared hydrogels, where the $\mathrm{pH}$, time of loading and BSA concentrations have been shown a significant effects on maximum loading percentages. Finally, the cumulative release percentages $\mathrm{R}_{\text {cum }}$ of BSA protein from the prepared hydrogels were examined in different $\mathrm{pH}$ and temperatures of the release medium. The hydrogels after release the protein have shown morphological surface from SEM images filled with holes and remain stable where they can be used again.
\end{abstract}

Keywords: Natural Polymers, Sustainable Release, Blend Polymers, Hydrogels, Bovine Serum Albumin

\section{Introduction}

Hydrogels are three dimensional polymers have hydrophilic and insoluble groups with cross-linked networks. A large amount of water can uptake inside the hydrogel network [1, 2]. Hydrogels may swell up to thousands of times of their dry weight in water [3]. Dispersion of water in hydrogels will changes to colloidal gels [4]. The hydrophilic groups such as $-\mathrm{OH},-\mathrm{CONH},-\mathrm{COOH},-\mathrm{SO}_{3} \mathrm{H}$, and $-\mathrm{NH}_{2}$ are increase the ability of the hydrogels to absorb water [5]. Integrity, biocompatibility and flexibility are the most important factors which help the hydrogels of hydrophilic 
three dimensional matrices to be us as carrier materials. The industrial prepared hydrogels from different type of monomers have shown many uses especially in tissueengineering scaffolds, Sustained release or for carry of implantable devices [6, 7]. The hydrogels are often crosslinked either chemically or physically [1]. Most of the hydrogels and because of their functional groups are responding to the external stimuli where their volume or wetting characteristics change under slide change in temperature, $\mathrm{pH}$, pressure, solvent, electric fields and ionic strength.

Polyvinyl alcohol (PVA) the hydrophilic polymer with semi-crystalline structure made of linear synthetic polymer where PVA is produced commercially from polyvinyl acetate [8-12]. It has water soluble nature and insoluble in organic solvent except slightly soluble in ethanol [11]. It has good mechanical, biodegradable and biocompatible properties and it can form good films [12].

Natural or semi-natural polymers are used in the preparation of hydrogels with PVA (more often through blending) such as amylopectin the polysaccharide with its short linear chains and have a branched structure [13-15]. The high viscosity of amylopectin [14] is due to it is composed of clusters which are connected by long chains. In addition, Shellac the animal origin resin. It is a natural polymer and similar chemically to synthetic polymers with plastic nature $[15,16]$. Shellac has a poor mechanical property and instability and it gives a brittle and impervious coating [17].

However, the starch with its biodegradability and its availability and low cost, it is considered one of the most important. Starch, in its natural state is exists in a granular and has unique properties [18]. Therefore, combining natural polymers with starch can provide individual advantages like starch-based biodegradable polymers in the form of microsphere or hydrogel can be used for drug delivery [19]. Finally, Ethyl cellulose is the derivative of cellulose which is slightly hygroscopic, odorless and tasteless powder. It is insoluble in water, but soluble in certain organic solvents depending upon the ethoxyl content. Ethyl cellulose is a stabilizer and thickener for foods [20] and because it is soluble in gastric juice and swell so it can be use in drug release $[20,21]$.

In the present work, poly (vinyl alcohol) PVA was used for preparation of new hydrogels through blending with the following natural polymers; amylopectin $\mathrm{AP}$, shellac $\mathrm{SH}$, and starch STand semi-natural polymer ethyl cellulose EC. For comparison glutaraldehyde GLU the chemical cross linker and sodium hexametaphosphate SHMP the physical cross linker were used. The degree of swelling of the prepared hydrogels was measured in different $\mathrm{pH}$ medium. Moreover, loading of BSA protein on different hydrogels with different concentrations and in different time intervals were investigated, and the cumulative release of the loaded BSA from the hydrogels under different release medium conditions of $\mathrm{pH}$ and temperatures of were analyzed.

\section{Experimental}

\subsection{Materials}

Poly (vinyl alcohol) PVA granular ( $\overline{\mathrm{M}} \mathrm{v}=101,000$ g.mol-1) was obtained from Qualiquens, India and used without purification. Amylopectin AP ( $\overline{\mathrm{M}} \mathrm{v}=280,000$ g.mol-1), starch ST ( $\overline{\mathrm{M}} v=105,700$ g.mol-1), ethyl cellulose EC $(\overline{\mathrm{M}} \mathrm{v}=310,000$ g.mol-1) were obtained from $\mathrm{BDH}$, UK and shellac $\mathrm{SH}$ ( $\overline{\mathrm{M}} \mathrm{v}=1,500$ g.mol-1) was obtained from Sigma-Aldrich, UK. The cross-linkers glutaraldehyde GLU (50wt \%) and sodium hexametaphosphate SHMP were obtained from Fluka SW and $\mathrm{BDH}$, respectively. Bovine serum albumin BSA and other chemicals were analytical grade reagents were received from Fluka.

\subsection{Hydrogels Preparation}

In separate beakers, $10 \mathrm{ml}$ of $10 \% \mathrm{w} / \mathrm{v}$ aqueous solutions of PVA polymer were prepared. The average molecular weights of the used polymers were depended to prepare blending in equal mole concentration of $10^{-3} \mathrm{M}$ from natural polymers with PVA. Where in separate beakers, aqueous solution of 5 $\mathrm{ml}$ of $28 \% \mathrm{w} / \mathrm{v}$ of AP, hot aqueous solution of $10 \mathrm{ml}$ of $11 \%$ $w / v$ of ST, ethanol solution of $10 \mathrm{ml}$ of $0.1 \% w / v$ of SH and ethanol solution of $5 \mathrm{ml}$ of $31 \% \mathrm{w} / \mathrm{v}$ of EC, were prepared and then has been added individually into PVA solution beakers [22]. For each mixture, $10 \mathrm{ml}$ of $5 \% \mathrm{w} / \mathrm{v}$ of the initiator ammonium persulfate APS was added. Subsequently, the final collected solutions were divided into two portions and for each, either $5 \mathrm{ml}$ of $30 \% \mathrm{w} / \mathrm{v}$ aqueous solution of SHMP as physical cross-linker or $0.5 \mathrm{ml}$ of $50 \mathrm{wt} \%$ GLU as chemical cross-linker was added quickly and with vigorous mixing to avoid the fast agglomeration of the solution. For homogenize products one hour extra mixing was continued. Finally, the beakers were left in the oven at less than $60^{\circ} \mathrm{C}$ until dried.

\subsection{Characterizations of the Prepared Hydrogels}

\subsubsection{FT-IR Spectroscopy}

Fourier Transformer Infrared spectrophotometer type Shimazdu IR- Affinity/ Japan instrument was used for characterization of the prepared hydrogels in the spectral region $500-4000 \mathrm{~cm}^{-1}$. Where the absorption frequencies of the chemically cross linked hydrogels are shows in Table 1, and the absorption frequencies of the physically cross linked hydrogels are shows in Table 2, beside their absorption frequencies after loading with the BSA protein.

\subsubsection{X-ray Diffraction}

XRD-P analytical type, made of Netherland at 2013 was used for measuring of X-ray diffraction for the pristine hydrogels for characterization of their crystal structures. Where the measurements are record up to $2 \theta$ scale in an angle range of $5^{\circ}-90^{\circ}$ at a scan speed of $1 \%$ min using copper/Indium (0.9/0.1) 100\% radiation target and nickel filter at a current of around $20 \mu \mathrm{A}$ a voltage of $35 \mathrm{kv}$. The crystallinity percentages and other XRD intensity scans 
values of the prepared hydrogels were given in Table 3.

The crystallinity percentage $\left(\% \mathrm{X}_{\mathrm{c}}\right)$ was calculated according to:

$$
\% X_{c}=\frac{\mathrm{Ac}}{\mathrm{Aa}+\mathrm{Ac}} \times 100
$$

Where, $A_{c}$ and $A_{a}$ are the area of crystalline and amorphous phases, respectively.

\subsubsection{Thermal Analysis}

Differential thermal analysis DTA of the prepared hydrogels were investigated using DTA-60/ Simultaneous DTA-TG, Apparatus, Shimazdu/ Japan instrument with heating rate of $10^{\circ} \mathrm{C} / \mathrm{min}$ in nitrogen atmosphere. The BSA loaded and unloaded hydrogels were investigated and their results of DTA, maximum temperature decomposition $T_{\max }$ and glass transition temperature $\mathrm{T}_{\mathrm{g}}$ and other thermal parameters were given in Table 4 and 5 .

\subsubsection{SEM Analysis}

The SEM micrographs of the prepared hydrogels were measured using TESCAN, Vega, III, 2011, Czech Republic instrument. The SEM images of some pristine hydrogels and their images after release of BSA were studied. Where double adhesive taps have been fixed on aluminum studs and the samples were mounted on it and then coated with cold ion under vacuum using beam sputter.

\subsection{Degree of Swelling DS Measurements}

The degree of swelling (DS) of the studied hydrogels prepared in small size pieces were measured. Dry hydrogel pieces with a fixed weight were immersed in distilled water and each $3 \mathrm{hrs}$ their precise weight has been measured after removal of all un-adsorbed water and even tissue paper for more drying has been used. The following equation for measuring the degree of swelling DS was depended [23].

$$
D S \%=\frac{W t-W_{\circ}}{W_{\circ}} \times 100
$$

Where, $\mathrm{W}_{\mathrm{t}} \& \mathrm{~W}_{\mathrm{o}}$ are the weight of swell hydrogel at time $t$, and the weight of dry hydrogel respectively. The effects of the $\mathrm{pH}$ swelling medium of $\mathrm{pH} 4, \mathrm{pH} 6$ and $\mathrm{pH} 8$ were investigated which represent acidic, neutral and basic swelling medium, respectively.

\subsection{Loading of BSA on Prepared Hydrogel}

The loading of the prepared hydrogels with BSA model has been investigated in different loading conditions. However, the time of loading and the $\mathrm{pH}$ of loading medium, beside the concentrations of BSA protein used for loading have been investigated to reach maximum loading. $100 \mathrm{mg}$ of the hydrogels were immersed in beaker contain $50 \mathrm{ml}$ of $2.0 \mathrm{~g} / \mathrm{L}$ BSA concentration and the maximum loading was examined in $\mathrm{pH} 4, \mathrm{pH} 6$ and $\mathrm{pH} 8$ for $12 \mathrm{hrs}$ at room temperature. Each 1.5 hrs the hydrogel sample were removed and the remain BSA solution was measured using UV-visible spectrophotometer (Jasco V-630 spectrophotometer/ Japan), where the instrument was fixed at $\lambda_{\max } 279 \mathrm{~nm}$ and the absorbance (A) was measured. The calibration curve was used for determination of the concentration of remain BSA solution. However, the favorable loading $\mathrm{pH}$ solution was fixed and the time of loading also measured at $(1.5,3.0,4.5$ and 6.0) hrs beside the BSA loading concentrations was changed between $(0.5,1.0,1.5$ and 2.0$) \mathrm{g} / \mathrm{L}$ for optimum loading conditions. The following equations were applied for determination of BSA maximum loading $\left(\mathrm{L}_{\max }\right)$ and efficiency of loading (EL) of the examined hydrogels [24].

$$
\begin{gathered}
\% \mathrm{~L}_{\max }=\frac{\text { Amount of BSA protien loaded on hydrogel }}{\text { Amount of hydrogel taken for loading }} \times 100 \\
\% \mathrm{EL}=\frac{\text { Amount of BSA protien loaded on hydrogel }}{\text { Amount of BSA protien taken for loading }} \times 100
\end{gathered}
$$

\subsection{Cumulative Release of Loaded BSA Protein from Hydrogels}

Hydrogels of different blends and cross linked and with BSA maximum loaded have been depended in their cumulative release. However, $100 \mathrm{mg}$ of BSA maximum loaded hydrogel were kept in $200 \mathrm{ml}$ of physiological saline (PS) solution prepared from $0.9 \% \mathrm{w} / v$ aqueous solution of $\mathrm{NaCl}$. The cumulative release of BSA from the hydrogel was measured each 3 hrs Using UV-Visible spectrophotometer and for time intervals of $12 \mathrm{hrs}$ by recording the absorbance A at $\lambda_{\max } 279 \mathrm{~nm}$ (the maximum wave length of BSA protein) for the solution of the release medium and with restitution with new PS solution. The cumulative release $\left(\mathrm{R}_{\text {cum }}\right)$ of BSA protein was calculated by the following equation [25].

$$
\text { Percent Cumulative Release }\left(\% \mathrm{R}_{\text {cum }}\right)=\frac{W t}{W_{\mathrm{o}}} \times 100
$$

Where, $W_{t} \& W_{o}$ are the amount of BSA protein released at time $t$, and total amount of BSA protein released finally.

The cumulative release $R_{\text {cum }}$ of the studied hydrogels were investigated under two variables is temperature of the release medium at $\left(15,25\right.$ and $\left.40^{\circ} \mathrm{C}\right)$ and $\mathrm{pH}$ of the medium $(\mathrm{pH} 4$, pH6 and $\mathrm{pH} 8$ ) respectively.

\section{Results and Discussion}

Prepared hydrogels by blending are usually retain the unique properties of their individual components, and the final hydrogels are combination of two or more different and unusual properties in one polymer structure.

Smart or intelligent polymers are recently prepared also called hydrogels that are responsive to external stimuli such as temperature, $\mathrm{pH}$ and have many applications in bioreleasing or bio-processing of many important biomaterials like protein.

\subsection{Hydrogels Characterization}

A new hydrogels were prepared from blending of Poly (vinyl alcohol) PVA with natural polymers AP, SH, ST, and semi natural polymer EC. The prepared hydrogels were cross linked physically and chemically. However, new hydrogels 
need characterizations to their chemical structures, crystalline structure, thermal behavior and morphological surface using different types of techniques. The goal of preparing new hydrogels is to applied in bioseparation and bioprocessing of some sensitive biomaterials like proteins. Therefore, the prepared hydrogels were used for loading and releasing of BSA as modern protein and examined under different conditions in order to reach the maximum loading percentages and efficient cumulative release.

Accordingly, the prepared pristine hydrogels are characterized depending on FT-IR specroscopy, besides the $\mathrm{X}$-ray diffraction XRD, thermal analyses and SEM images for selected hydrogels.

\subsubsection{FT-IR Studies}

The FT-IR spectra of PVA blend hydrogels have been studied and their absorption frequencies with their featured functional groups are gradate in Tables 1 and 2, and some distinct FT-IR Figures 1-4,

Table 1. FT-IR wavenumbers of the characteristic bands of hydrogels cross-linked chemically.

\begin{tabular}{|c|c|c|c|c|c|c|}
\hline \multirow{2}{*}{$\begin{array}{l}\text { Examined } \\
\text { Sample }\end{array}$} & \multicolumn{6}{|c|}{ Wavenumber of characteristic band, $\mathrm{cm}^{-1}$} \\
\hline & $\gamma(\mathrm{O}-\mathrm{H}) \mathrm{str}$ & $\gamma(\mathrm{C}-\mathrm{H}) \mathrm{str}$ & $\gamma(\mathrm{C}=\mathrm{O}) \mathrm{str}$ & $\gamma(\mathrm{C}-\mathrm{O}) \mathrm{str}$ & $\gamma(\mathrm{C}-\mathrm{O}-\mathrm{C}) \mathrm{str}$ & $\gamma(\mathrm{C}-\mathrm{H}) \mathrm{def}$ \\
\hline $\mathrm{AP} / \mathrm{P}-\mathrm{b}-\mathrm{CH}$ & $\begin{array}{l}3524 \\
1373\end{array}$ & $\begin{array}{l}2920 \\
3080\end{array}$ & $\begin{array}{l}1744 \\
1603\end{array}$ & 1450 & 1140 & 787 \\
\hline $\mathrm{ST} / \mathrm{P}-\mathrm{b}-\mathrm{CH}$ & 3462 & 2950 & $\begin{array}{l}1650 \\
1603\end{array}$ & 1100 & 1140 & 793 \\
\hline $\mathrm{SH} / \mathrm{P}-\mathrm{b}-\mathrm{CH}$ & 3505 & 3100 & $\begin{array}{l}1726 \\
1402\end{array}$ & 1148 & 1148 & 793 \\
\hline
\end{tabular}

Table 2. FT-IR wavenumbers of the characteristic bands of hydrogels cross-linked physically.

\begin{tabular}{|c|c|c|c|c|c|c|c|}
\hline \multirow{2}{*}{$\begin{array}{l}\text { Examined } \\
\text { Sample } \\
\end{array}$} & \multicolumn{7}{|c|}{ Wavenumber of characteristic band, $\mathbf{c m}^{-1}$} \\
\hline & $\gamma(\mathrm{O}-\mathrm{H}) \mathrm{str}$ & $\gamma(\mathrm{C}-\mathrm{H}) \mathrm{str}$ & $\gamma(\mathrm{C}=\mathbf{O}) \mathrm{str}$ & $\gamma(\mathrm{C}-\mathrm{O}) \mathrm{str}$ & $\gamma(\mathrm{C}-\mathrm{O}-\mathrm{C}) \mathrm{str}$ & $\gamma(\mathrm{C}-\mathrm{H}) \mathrm{def}$ & $\gamma(\mathrm{P}-\mathrm{O}-\mathrm{P}) \mathrm{str}$ \\
\hline $\mathrm{AP} / \mathrm{P}-\mathrm{b}-\mathrm{PH}$ & $\begin{array}{l}3495, \\
1350\end{array}$ & 3080 & $\begin{array}{l}1747 \\
1603\end{array}$ & 1404 & 1150 & 795 & $\begin{array}{l}720,1150 \\
1100,1260\end{array}$ \\
\hline $\mathrm{ST} / \mathrm{P}-\mathrm{b}-\mathrm{PH}$ & 3499 & 2960 & $\begin{array}{l}1650 \\
1603\end{array}$ & 1404 & 1157 & 795 & $\begin{array}{l}710,1145 \\
1100,1255\end{array}$ \\
\hline $\mathrm{SH} / \mathrm{P}-\mathrm{b}-\mathrm{PH}$ & 3547 & $\begin{array}{l}2839 \\
2910\end{array}$ & $\begin{array}{l}1713 \\
1650\end{array}$ & 1458 & 1150 & 797 & $\begin{array}{l}720,1150, \\
1100,1280\end{array}$ \\
\hline
\end{tabular}

Where shows the characteristic peaks represent the more characteristic functional groups of the different polymers blend PVA hydrogels which cross-linked chemically with GLU or physically with SHMP.

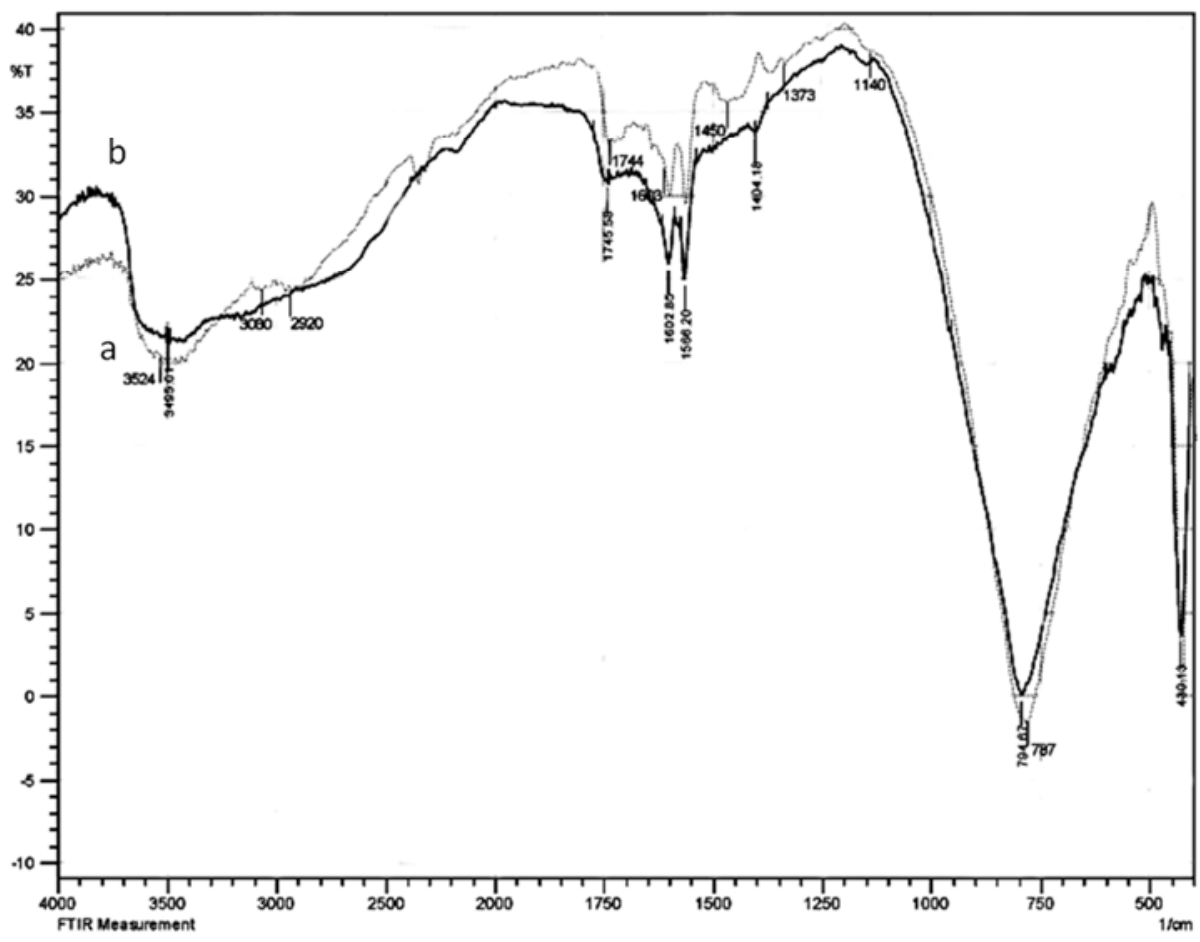

Figure 1. FT-IR spectra of $a-A P / P-b-C H$ hydrogel and $b-A P / P-b-P H$ hydrogels. 


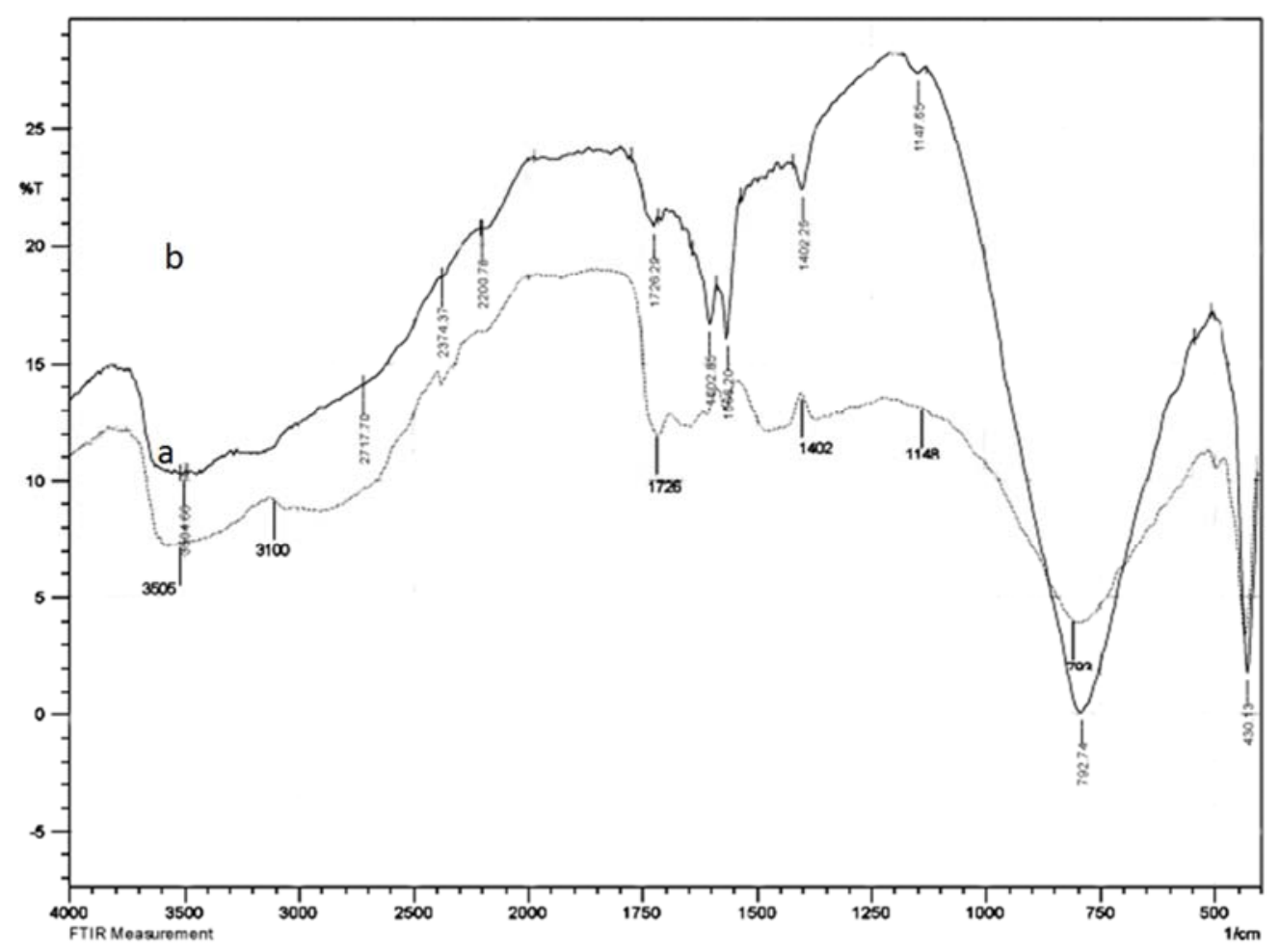

Figure 2. T-IR spectra of $a-S H / P-b-C H$ hydrogel and $b-S H / P-b-P H$ hydrogels.

Whereas, the characteristic bands of AP/P-b-CH represent amylopectin blend PVA and cross linked chemically, Figure 1 and Table 1, have shown wavenumbers at (3524 and $1373) \mathrm{cm}^{-1}$ represent $\gamma(\mathrm{O}-\mathrm{H}) \mathrm{str}$, and at $(2920$ and 3080$) \mathrm{cm}^{-1}$ represent $\gamma(\mathrm{C}-\mathrm{H})$ str, and at $(1744$ and 1603$) \mathrm{cm}^{-1}$ represent $\gamma(\mathrm{C}=\mathrm{O})$ str, and at $1450 \mathrm{~cm}^{-1}$ represent $\gamma(\mathrm{C}-\mathrm{O}) \mathrm{str}$, and at 1140 $\mathrm{cm}^{-1}$ represent $\gamma(\mathrm{C}-\mathrm{O}-\mathrm{C})$ str. Finally, the band at $787 \mathrm{~cm}^{-1}$ represent $\gamma(\mathrm{C}-\mathrm{H})$ def. The previous mentioned characteristic bands indicate that sometimes interferences occur in the characteristic peaks of both blend polymers and even groups of cross-linker. The other characteristic bands mentioned in Table 1, Figures 2, 3 and 4, are belong to ST/P-b-CH which represent starch blend PVA, and $\mathrm{SH} / \mathrm{P}-\mathrm{b}-\mathrm{CH}$ which represent shellac blend PVA, and EC/P-b-CH which represent ethyl cellulose blend PVA and all are cross linked chemically, respectively $[2,4-7,26]$.

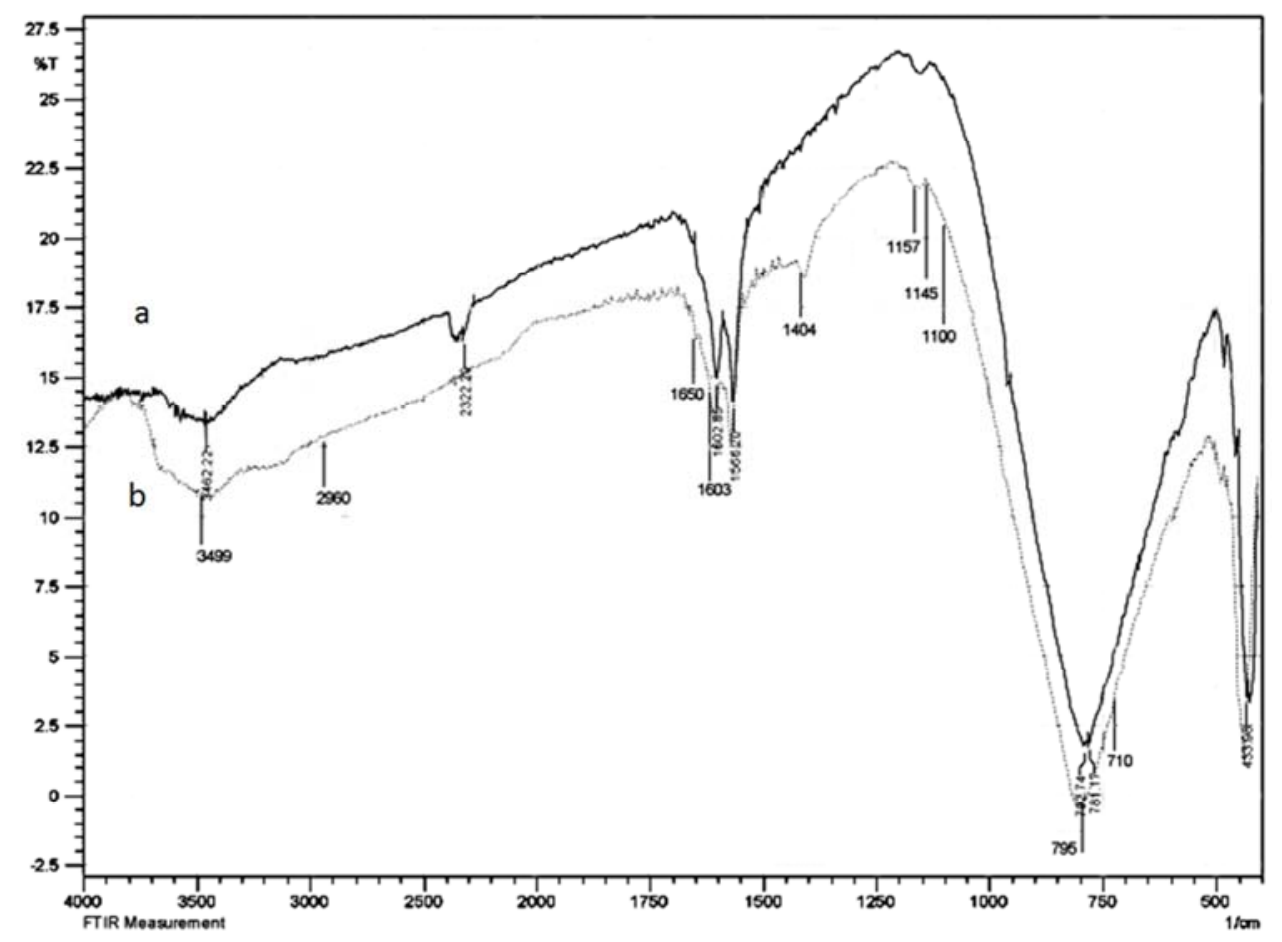

Figure 3. FT-IR spectra of a-ST/P-b-CH hydrogel and b-ST/P-b-PH hydrogels. 


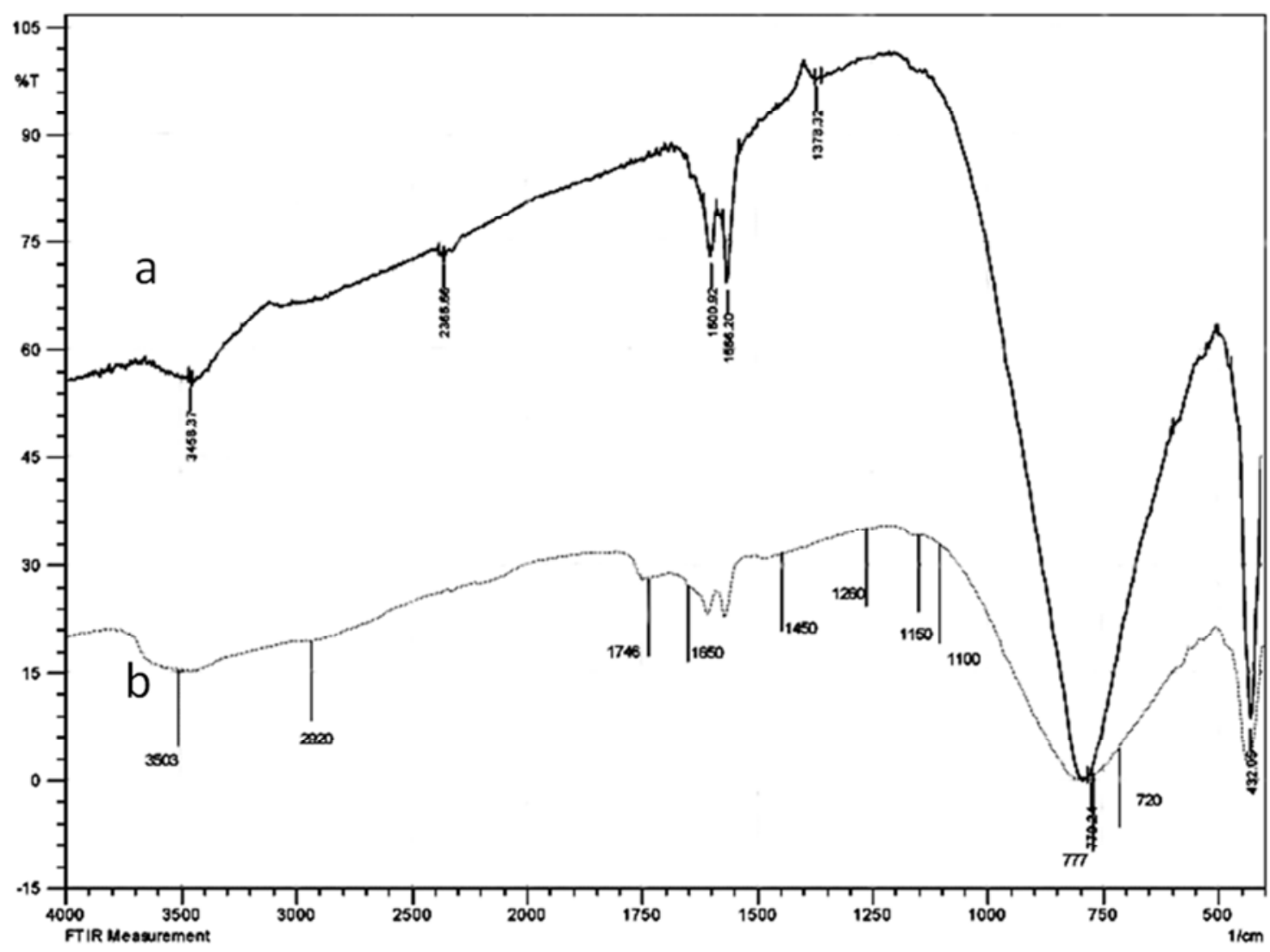

Figure 4. FT-IR spectra of $a-E C / P-b-C H$ hydrogel and $b-E C / P-b-P H$ hydrogels.

The previous blend hydrogels are also cross linked physically and gradate in Table 2 and their characteristic peaks are shows in Figures 1, 2, 3and4 and are as follows AP/P-b-PH, ST/P-b-PH, SH/P-b-PH and EC/P-b-PH which are shows almost same wavenumbers of characteristic bands except those of the physical cross linker SHMP which their frequencies appear at $\left(722,1150,1100\right.$ and 1280) $\mathrm{cm}^{-1}$ which represent the $\gamma(\mathrm{P}-\mathrm{O}-\mathrm{P})$ str band of SHMP appeared [27].

\subsubsection{Degree of Swelling DS Investigations}

The degree of swelling DS of the prepared hydrogels in different $\mathrm{pH}$ swelling medium and in $0.1 \mathrm{~N}$ saline solution were studied in order to reach the best degree of swelling conditions.

However, the degrees of swelling of AP/P-b-CH and AP/Pb-PH hydrogels were measured according to the Equation (2) using swelling medium of $\mathrm{pH} 4, \mathrm{pH} 7$ and $\mathrm{pH} 9$ in addition to $0.1 \mathrm{~N} \mathrm{NaCl}$. Figure 5 shows significant effects of $\mathrm{pH}$ or ionic solution of swelling medium on DS [28].

The amylopectin blend PVA hydrogel Figure 5 has shown two points, where the degree of swelling percentage DS\% of AP/P-b-PH hydrogel in $\mathrm{pH} 9$ swelling medium reach about 28 hundred times higher than its original volume. In addition the AP/P-b-PH hydrogels in all examined swelling solutions have higher DS\% in comparison with chemical cross-linked hydrogels Figure 5, because amylopectin has only hydroxyl groups and when hydrolyses will produce anions [29] would be in repulsion with $\mathrm{pH} 9$ anions of the medium in addition to the anions of the cross linker SHMP, and the final result was spacing of the hydrogel chains.

Similarly, in $\mathrm{pH} 7$ and $\mathrm{pH} 4$ the repulsion between the hydrogel anions and of SHMP will let the physical cross linked hydrogels swell higher than those of chemically cross-linked Figure 5. However, in both $\mathrm{pH} 7$ and $\mathrm{pH} 4$ the hydrogels were swelling less than $\mathrm{pH} 9$ due to the absence of the swelling medium anions and less more in $\mathrm{pH} 4$ Figure 5, because of the $\mathrm{pH} 4$ cations which decrease the space between chains.

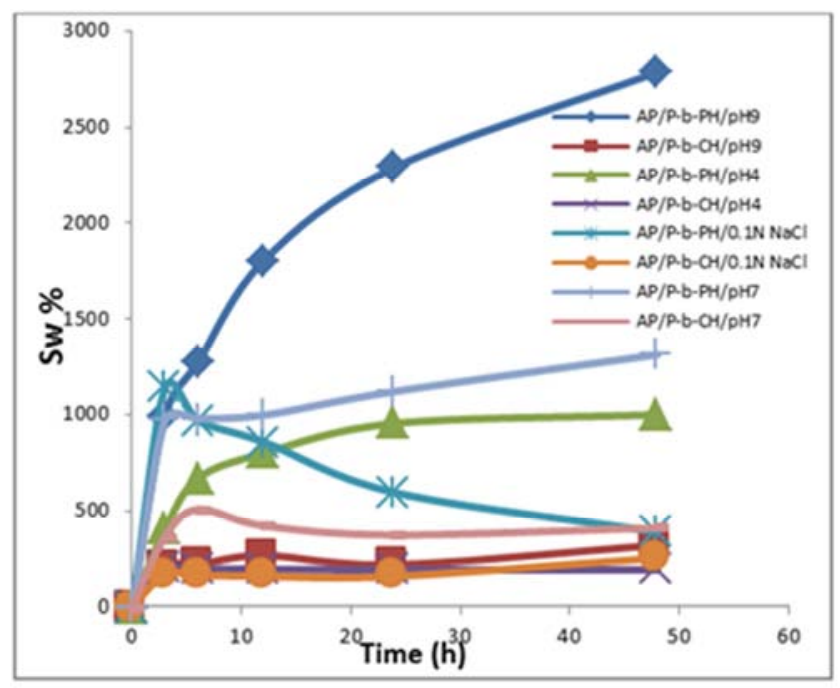

Figure 5. Effects of $p H \&$ saline solution on $S_{w} \%$ of $A P / P-b-C H$ and $A P / P-b-$ PH hydrogels. 


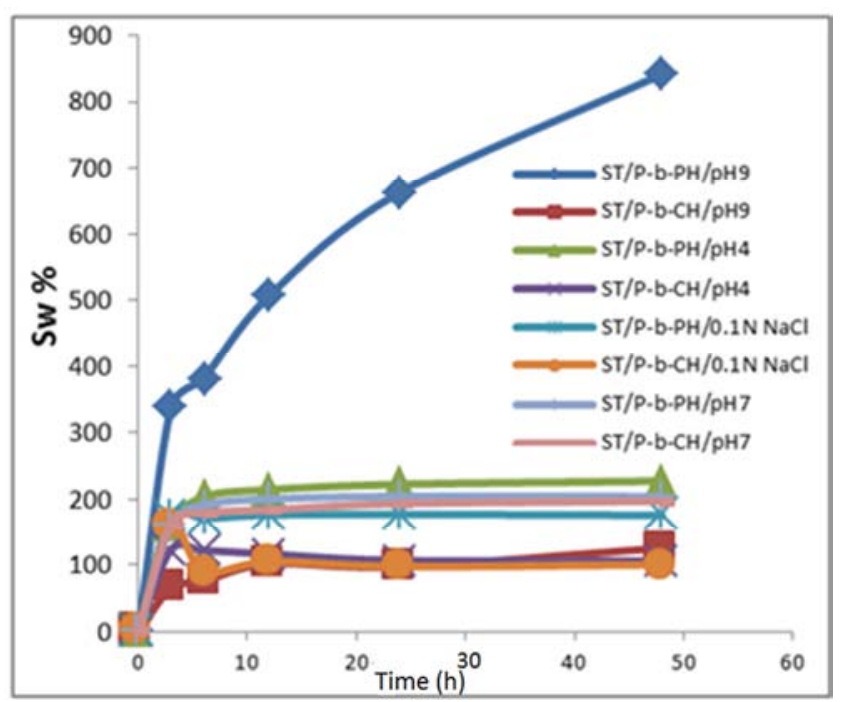

Figure 6. Effects of $p H \&$ saline solution on $S_{w} \%$ of ST/P-b-CH and ST/P-bPH hydrogels.

Similarly, hydrogels made of starch blend PVA Figure 6 have shown almost the same swelling behavior as amylopectin blend PVA hydrogels Figure 5 with less degree of swelling DS\% in comparison with amylopectin hydrogels, and this is because starch is consist of amylose and amylopectin molecules [30] and because amylopectin is branched whereas amylose is linear and helical in its structure and the aforesaid has no three dimensional structure for increasing the volume of the hydrogel on swelling like amylopectin structure.

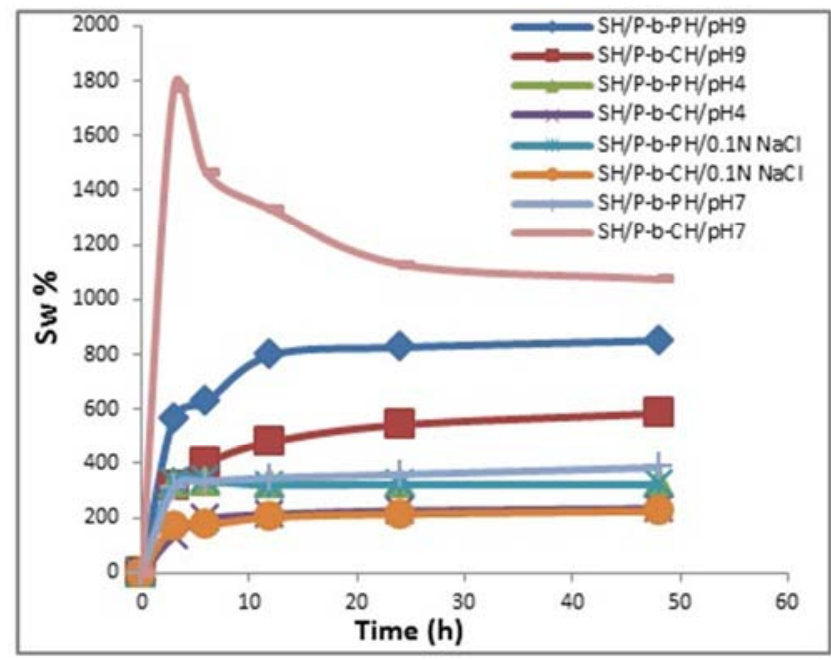

Figure 7. Effects of $p H \&$ saline solution on $S_{w} \%$ of $S H / P-b-C H$ and $S H / P-$ b-PH hydrogels.

Shellac SH, the natural polymer has carboxylic acid groups in its structure which can easily hydrolyze in swelling medium [31]. Therefore in $\mathrm{pH} 9$ medium neutralization will occurred and effect on DS\% of the hydrogel. Therefore, $\mathrm{SH} / \mathrm{P}-\mathrm{b}-\mathrm{CH}$ hydrogel in $\mathrm{pH} 7$ medium has shown the highest degree of swelling Figure 7, because no ions are there in the swelling medium. But however a sharp decrease in DS\% in $\mathrm{pH} 7$ would occurred after some hours of swelling Figure 7, is because the hydrogel would lose some of its weight due to the hydrolysis of the shellac polymer inside the swelling medium.

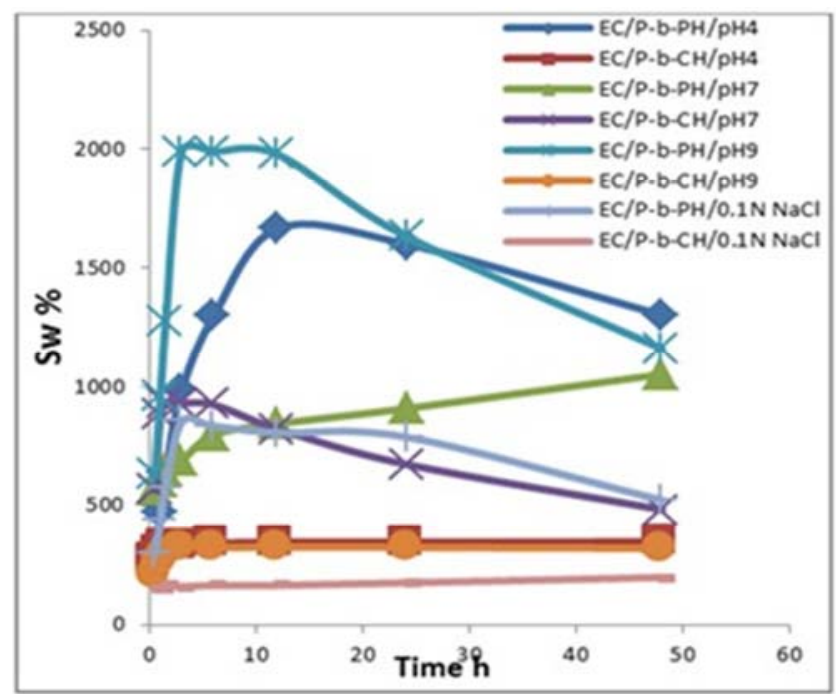

Figure 8. Effects of $p H \&$ saline solution on $S_{w} \%$ of EC/P-b-CH and EC/Pb-PH hydrogels.

Ethyl cellulose EC, the derivative of cellulose when swell, some of its hydroxyl groups are converting into ethyl ether groups. Blending of EC with PVA will produce hydrogel have folded morphological structure with high porous. Therefore, the degree of swelling DS\% of EC blend PVA hydrogel is high [32]. Moreover, and because of the hydroxyl groups of the ethyl cellulose, therefore its hydrogel inside swelling medium act as anionic polymer and for that its DS\% is high especially for physically cross linked hydrogels because of its anions and the $\mathrm{pH} 9$ anions which together will push the hydrogel chains for repulsion and finally its DS\% will increase Figure 8.

\subsubsection{X-ray Diffraction Studies}

The X-ray diffraction analysis means scatting or diffraction of X-ray radiation by electrons present in the tested material. Therefore, the regular structure means crystalline material which scattered it in maxima, but the diffracted intensity is low and in broad for amorphous material. Generally, the crystallographic structure of the material and its atomic composition can be determined from $\mathrm{x}$-ray diffraction pattern from the position and intensity of the maxima [33].

The XRD pattern data shown in Table 3 represent some of the studied chemical and physical cross linked hydrogels. 
Table 3. XRD intensity scans values of chemically and physically cross-linked hydrogels.

\begin{tabular}{|c|c|c|c|c|c|c|}
\hline $\begin{array}{l}\text { Examined } \\
\text { Sample }\end{array}$ & Peaks at $2 \theta^{0}$ & $\begin{array}{l}\text { Interplanar distance } \\
\text { "d" }\left(\mathbf{A}^{0}\right)\end{array}$ & FWHM $\left(\mathbf{A}^{0}\right)$ & $\begin{array}{l}\text { Crystalline } \\
\text { phase } \mathbf{A}_{\mathbf{c}}\left(\mathbf{A}^{0}\right)\end{array}$ & $\begin{array}{l}\text { Amorphousness } \\
\text { phase } \mathbf{A}_{\mathbf{a}}\left(\mathbf{A}^{0}\right)\end{array}$ & $\begin{array}{l}\text { Crystal. Percent. \% } \mathbf{X}_{\mathrm{c}} \text {, } \\
\text { Equate1 }\end{array}$ \\
\hline \multirow{3}{*}{ AP/P-b-CH } & 42.139 & 2.144 & 0.409 & 55.57 & 243.54 & 18.58 \\
\hline & 44.698 & 2.027 & 0.807 & 30.86 & 243.82 & 11.23 \\
\hline & 72.636 & 1.302 & 0.512 & 36.11 & 204.29 & 15.02 \\
\hline \multirow{6}{*}{ SH/P-b-PH } & 5.227 & 16.907 & 0.614 & 17.75 & 520.03 & 3.30 \\
\hline & 20.815 & 4.268 & 0.921 & 418.04 & 544.68 & 43.42 \\
\hline & 42.064 & 2.148 & 0.154 & 79.62 & 1056.86 & 7.01 \\
\hline & 49.237 & 1.851 & 0.205 & 50.57 & 984.57 & 4.88 \\
\hline & 72.662 & 1.301 & 0.230 & 599.98 & 911.69 & 39.69 \\
\hline & 88.317 & 1.107 & 0.461 & 289.52 & 911.07 & 24.11 \\
\hline \multirow{2}{*}{ ST/P-b- CH } & 44.691 & 2.028 & 0.204 & 31.11 & 254.96 & 10.87 \\
\hline & 72.576 & 1.303 & 0.256 & 25.35 & 210.94 & 10.73 \\
\hline
\end{tabular}

Whereas the data are calculate precisely from Figure 9.
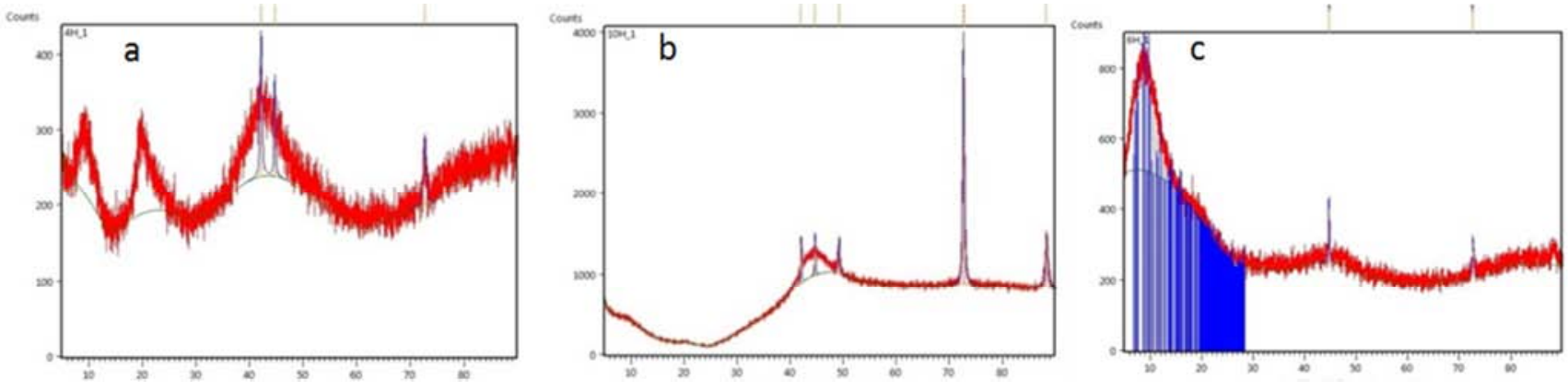

Figure 9. XRD pattern $a-A P / P-b-C H, b-S H / P-b-P H, c-S T / P-b-C H$ hydrogels.

However, the XRD patterns give good events about the components of the blend hydrogels and excellent view about their crystallinity and crystal structure. Where the XRD diffract grams and the data entered in Table 3 are clear and with no doubt that the pure PVA is highly crystalline but blending it with other polymer would produce new hydrogel and do depression in its crystallinity. This depression depends to a certain degree on crystallingraphic structure of the added natural polymer, beside the type of the cross-linker material. Where the data have shown that physical cross- linker such as SHMP has significant effects on the elevation of the crystallinity of the hydrogel in comparison with the chemical cross-linker GLU. As a result, the degree of crystallinity of the PVA will reduce due to the blending that will collapse the regularity formed by the hydrogen bonding between the PVA chains [33].

The XRD pattern of AP/P-b-CH hydrogel Table 3, Figure 9a were shown five peaks some are intense and other are broad. The three intense peaks at $2 \theta^{\circ}$ of $(42.139,44.698$ and 72.636) were shown crystallinity percentage of $(18.58,11.23$ and 15.02$) \%$ respectively, means low crystalline structure after blending of the hydrogel due to the changes in its composite structure and low crystallinity is more suitable for the hydrogel for loading and releasing [34].

The presence of sodium ions in the physically cross-linked hydrogel comes from SHMP will elevate its degree of crystallinity, although the hydrogel is blends with the natural polymer of low crystalline structure [35].

Therefore, SH/P-b-PH hydrogel has shown XRD pattern with peaks appeared with sharp and narrow shape Table 3 and Figure $9 \mathrm{~b}$, and at $2 \theta^{\circ}$ of (20.815 and 72.66) which have shown high crystallinity percentage of (43.42 and 39.69) \% and even the crystallinity percentage of SHMP characteristic peak was increased and record at $24.11 \%$, and as a result, the final crystallinity of the whole hydrogel structure would elevate.

Finally, the XRD pattern of ST/P-b-CH hydrogel has shown also low crystalline structure even in comparison with AP/P-b-CH. Where broad shape peaks with less number are appeared as shown in Table 3 and Figure 9c, where ST/P-b$\mathrm{CH}$ hydrogel has recorded its peaks at $2 \theta^{\circ}$ of (44.691and 72.576) and gave low crystallinity percentage of (10.87 and $10.73) \%$, means the hydrogel is tend to the amorphous structure after bending.

\subsubsection{Thermal Studies}

Thermal studies of some prepared hydrogels were examined and the differential thermal analysis DTA was depended for studying the pristine hydrogels before loading. The DTA thermograms studies supplies thermal information includes thermal stability and some transitions such as endothermic and exothermic transitions as a function of temperature.

The thermal data recorded in Table 4 give thermal characterizations of some studied hydrogels.

Table 4. DTA thermal data of some hydrogels cross-linked chemically and physically.

\begin{tabular}{lllll}
\hline Examined sample & $\mathbf{T}_{\mathbf{g}}\left({ }^{\mathbf{0}} \mathbf{C}\right)$ & $\mathbf{T}_{\max }\left({ }^{\mathbf{0}} \mathbf{C}\right)$ & $\mathbf{T}_{\text {cr }}\left({ }^{\mathbf{0}} \mathbf{C}\right)$ & $\Delta \mathbf{H}_{\mathbf{f}}\left(\mathbf{J}^{-g^{-1}}\right)$ \\
\hline AP/P-b-CH & 67.7 & 293 & 255 & $+5.0 ;-59.9$ \\
ST/P-b-CH & 73.8 & 433 & 404 & $+62.3 ;-38.0$ \\
EC/P-b-CH & 110.2 & 425 & 392 & $+36.2 ;-16.4$ \\
EC/P-b-PH & 95.7 & 430 & 395 & $+4.7 ;-3.5$ \\
SH/P-b-PH & 104.5 & 397 & 341 & $+15.1 ;-34.4$ \\
\hline
\end{tabular}


Where the AP/P-b-CH hydrogel has shown Table 4, Figure 10a glass transition temperature $\mathrm{T}_{\mathrm{g}}$ at $67.7^{\circ} \mathrm{C}$ means the hydrogel is thermally stable, and its crystalline temperature $\mathrm{T}_{\mathrm{cr}}$ and its maximum decomposition temperature $\mathrm{T}_{\max }$ at $255^{\circ} \mathrm{C}$ and $293^{\circ} \mathrm{C}$ respectively, means the hydrogel at $255^{\circ} \mathrm{C}$ start loss its crystalline structure and be ready for decomposition at $293^{\circ} \mathrm{C}$ and loss its structure. The heat of fusion $\Delta \mathrm{H}_{\mathrm{f}}$ of the hydrogel gives two important transitions Table 4, Figure 10a, one represent endothermic transition of $+5.0 \mathrm{~J} . \mathrm{g}^{-1}$, give indications that the hydrogel has some crystalline portions in its morphology therefore it need some energy for decomposition.

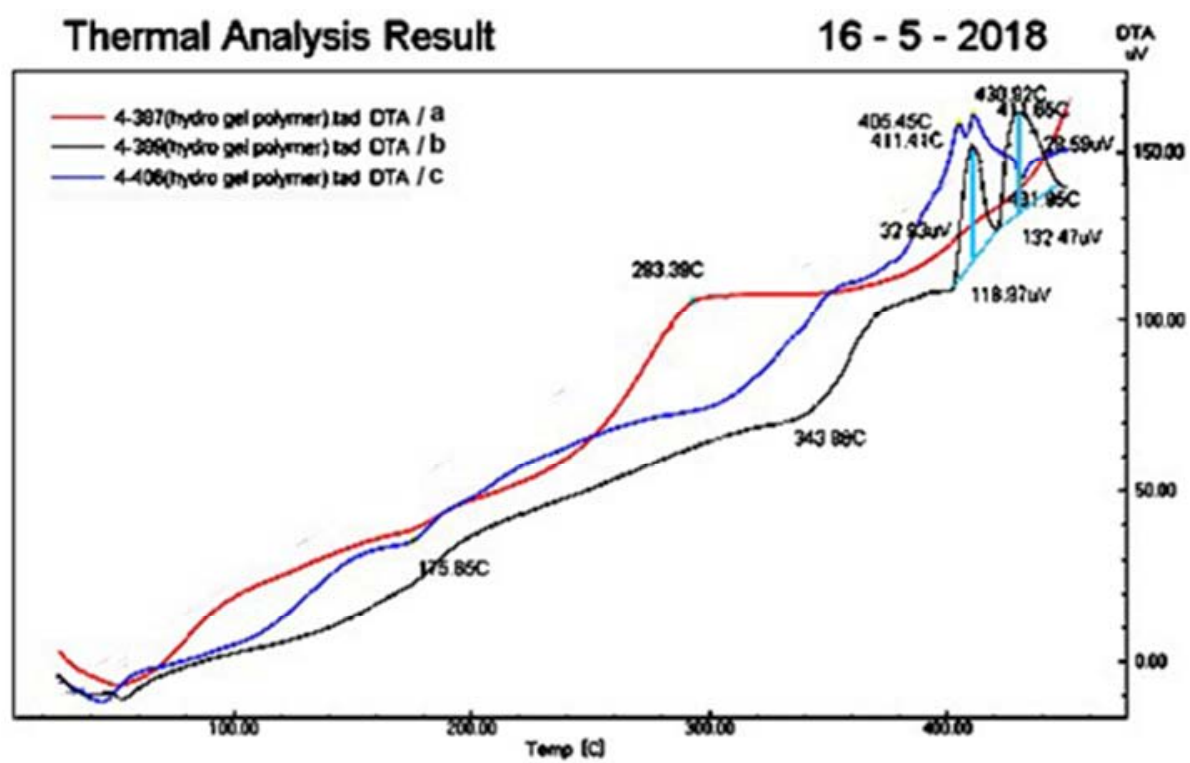

Figure 10. DTA of $a-A P / P-b-C H, b-S T / P-b-C H$, and $c-E C / P-b-C H$ hydrogels.

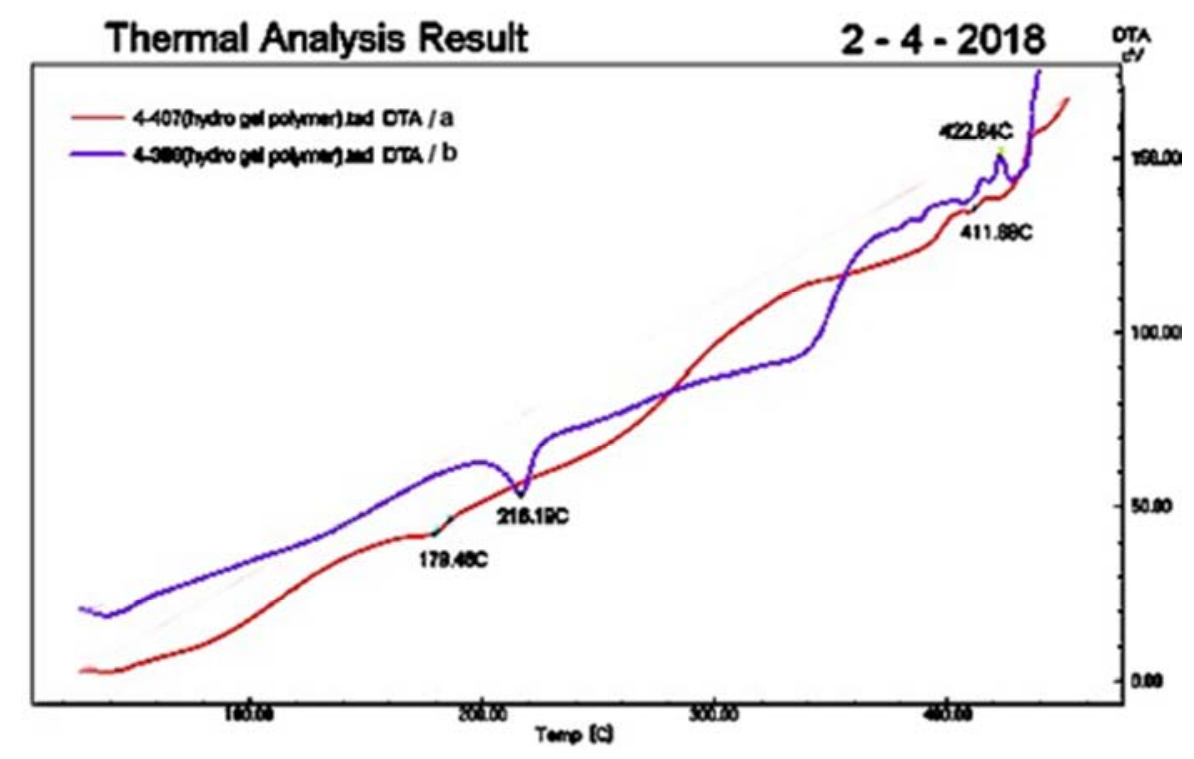

Figure 11. DTA of $a-E C / P-b-P H$, and $b-S H / P-b-P H$ hydrogels.

Whereas the second transition of-59.9 J.g ${ }^{-1}$ means the hydrogel has amorphous portions and on decomposition will liberate energy of $59.9 \mathrm{~J} \cdot \mathrm{g}^{-1}$ of the hydrogel [36]. In comparison, the ST/P-b-CH and even EC/P-b-CH hydrogel have shown Figure 10b, c and Table 4, thermally stabile hydrogels as it is clear from their high $\mathrm{T}_{\mathrm{g}}, \mathrm{T}_{\max }$ and $\mathrm{T}_{\mathrm{cr}}$. In addition the $\Delta \mathrm{H}_{\mathrm{f}}$ for both hydrogels are shows high endothermic transitions means thermally stable with low exothermic transitions [37].

On the other hand, the physical cross-linking hydrogels
Table 4 and Figure 11 have shown completely different DTA thermograms. The EC/P-b-PH hydrogel has shown Figure 11a little depression in its thermal parameters represent $T_{g}$ and $\Delta \mathrm{H}_{\mathrm{f}}$ in comparison with $\mathrm{EC} / \mathrm{P}-\mathrm{b}-\mathrm{CH}$, means ethyl cellulose blend PVA polymer loss some of its thermal stability with physical cross link where ionic interactions compete with hydrogen bonding leads to loss some. Whereas $\mathrm{SH} / \mathrm{P}-\mathrm{b}-\mathrm{PH}$ hydrogel has shown higher $\mathrm{T}_{\mathrm{g}}$ and $\Delta \mathrm{H}_{\mathrm{f}}$ Table 4 , Figure $11 \mathrm{~b}$ means thermally is stable [38]. 


\subsubsection{SEM Micrograph Studies}

SEM micrographs and their surface morphologies of some blend PVA hydrogels cross-linked chemically and physically were studied. Where the SEM image of AP/P-b-CH hydrogel has shows Figure 12a, the hydrogel surface morphology be appear smooth with cracks, which indicate that the hydrogel blend materials are mixed homogeneously but the hydrogel surface seems to be brittle due to the high degree of bonding [30].
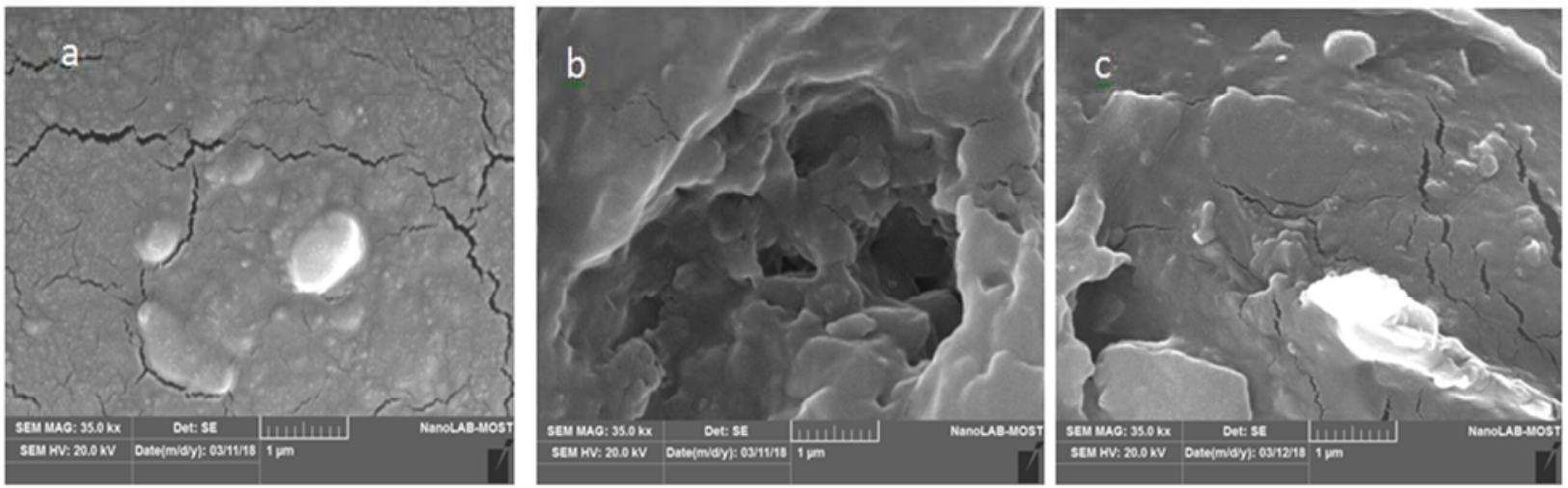

Figure 12. SEM micrograph of $a-A P / P-b-C H, b-S T / P-b-C H$ hydrogel and $c-E C / P-b-C H$.

Whereas the SEM image of ST/P-b-CH hydrogel Figure $12 \mathrm{~b}$, has shown irregular and fold surface with a lot of cavities and high degree of homogeneous blend polymers [37] which lead to wide surface area and high efficient for loading. Similarly, the SEM image of EC/P-b-CH hydrogel Figure $12 \mathrm{c}$ has shown non undulant surface with few uneven folds. Pores are spread inside and in between the folds which means the hydrogel could be present in elastic form and could be efficient in loading [39].

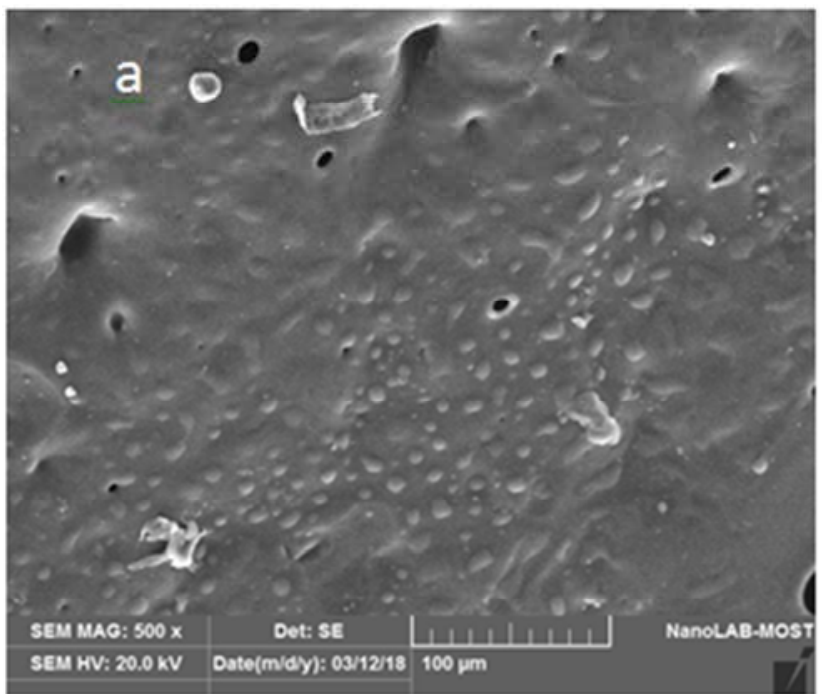

Whereas, the SEM images of physically cross linked PVA blend hydrogels has shown different surface morphologies, where the SEM micrograph of AP/P-b-PH hydrogel Figure 13a, has shown almost smooth and uniform surface with high number of pores and salience which would be help in high loadings. Likewise, the SEM micrograph of SH/P-b-PH hydrogel Figure 13b, has shown smooth and uniform surface contain some big holes could be useful also in loading [40].

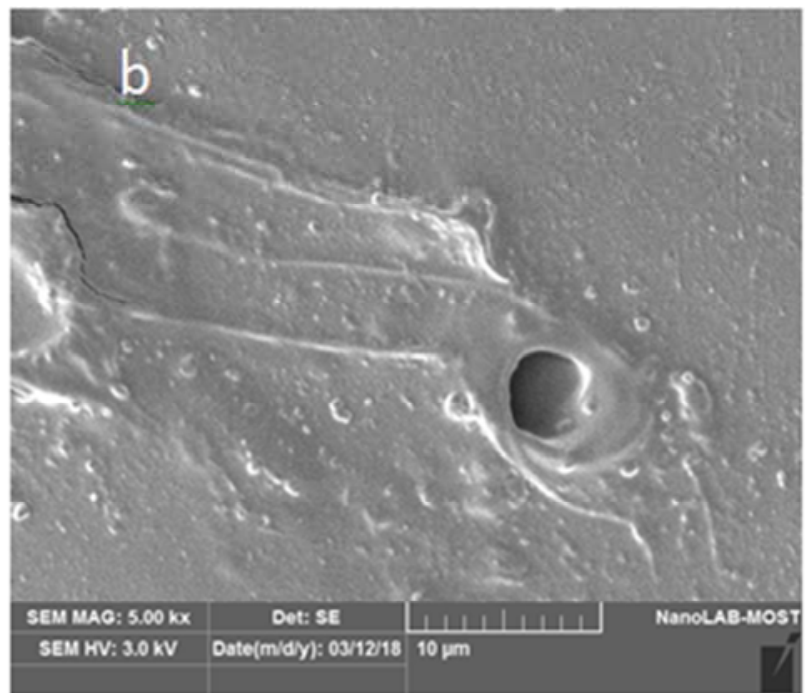

Figure 13. SEM micrograph of $a-A P / P-b-P H, b-S H / P-b-P H$ hydrogels.

\subsection{Loading of Hydrogels with BSA Protein}

The prepared hydrogels were loaded with BSA as model protein and for both chemically and physically cross linked. The BSA loading studies include investigation of $\mathrm{pH}$ of the loaded solution and different concentrations of loaded BSA. Some of the BSA loaded hydrogels were characterized using FT-IR spectroscopy and differential thermal analysis DTA, in order to confirm the loading of the BSA protein on the hydrogels.

\subsubsection{Characterization of BSA Loaded Hydrogels}

The BSA loaded hydrogels were characterized using FTIR spectroscopy technique and the examined samples were shown appearing of new characteristic frequencies represent the absorption bands of BSA loaded protein on studied hydrogels. The absorption bands which characterized in the examined spectra are of amide-I $\left(\gamma(\mathrm{C}=0)_{\text {str }}\right)$ represent the 
carbonyl functional group of BSA protein, beside absorption band of amide-II $\left(\gamma(\mathrm{N}-\mathrm{H})_{\text {str }}\right)$ represent the amine functional group of the protein.

The other common absorption frequencies are representing the characteristic bands of both blend polymers of the hydrogel components which have been already characterized in Table $1 \& 2$.

Similarly, the differential thermal analysis DTA of some loaded samples was studied and their final results are recorded in Table 5, Figure 14.

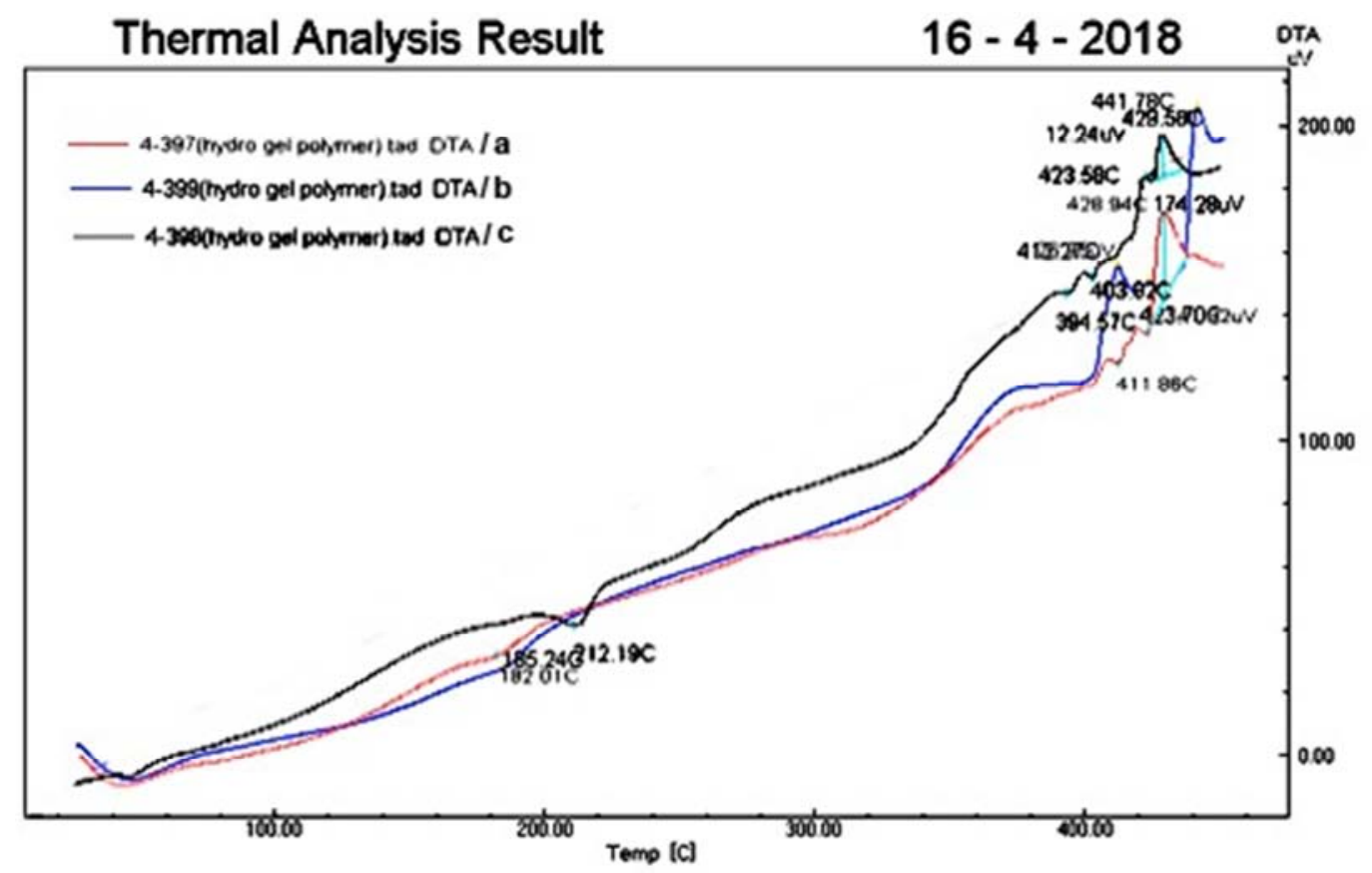

Figure 14. DTA thermogram of $a-A P / P-b-C H, b-S T / P-b-C H$, and $c-S H / P-b-P H$ hydrogels loaded with BSA protein.

Table 5. Thermal analysis parameters of some blend hydrogels loaded with BSA protein.

\begin{tabular}{lllll}
\hline Examine sample & $\mathbf{T}_{\mathbf{g}}\left({ }^{\circ} \mathbf{C}\right)$ & $\mathbf{T}_{\max }\left({ }^{\circ} \mathbf{C}\right)$ & $\mathbf{T}_{\text {cr }}\left({ }^{\circ} \mathbf{C}\right)$ & $\Delta \mathbf{H}_{\mathbf{f}}\left(\mathbf{J . g}^{-1}\right)$ \\
\hline AP/P-b-CH & 107.6 & 440 & 422 & $+13.5 ;-7.7$ \\
ST/P-b-CH & 100.2 & 422 & 402 & $+16.0 ;-3.6$ \\
SH/P-b-PH & 96.2 & 438 & 426 & $+8.8 ;-1.9$ \\
\hline
\end{tabular}

The thermal parameters of BSA loaded AP/P-b-CH hydrogel have shown complete changes after loading Table 5, Figure $14 \mathrm{a}$ in comparison with its parameters before loading Table 4, Figure 10a Where its $\mathrm{T}_{\mathrm{g}}, \mathrm{T}_{\max }$ and $\mathrm{T}_{\mathrm{cr}}$ are elevate into high degrees due to the formation of hydrogen bonding between the amide groups of BSA protein and the hydroxyl groups of the amylopectin and poly (vinyl alcohol) and form high crystalline structure for the final hydrogel and therefore, $\Delta \mathrm{H}_{\mathrm{f}}$ increase in its endothermic transitions from

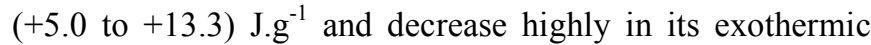

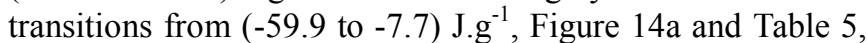
means the hydrogel became more crystalline after loading. Whereas the thermal parameters of BSA loaded ST/P-b-CH have shown Figure 14b, Table 5 increase in its $\mathrm{T}_{\mathrm{g}}$ from $(73.8$ to 100.2$)^{\circ} \mathrm{C}$, while both the endothermic and exothermic transitions are decreased from $(+47.7$ to +16.0$)$ and $(-38.0$ to $-3.6)^{\circ} \mathrm{C}$ respectively Figure $14 \mathrm{~b}$ and Table 5 , the elevation in its $\mathrm{T}_{\mathrm{g}}$ and the highly decrease in its exothermic transitions means ST/P-b-CH hydrogel get crystalline structure after loading but not stable like AP/P-b-CH hydrogel.
Whereas the SH/P-b-PH hydrogel of highly crystalline structure after be loaded with BSA protein has been lost and this is clear from its DTA thermal parameters, especially in its glass transition temperature $T_{g}$ and heat of fusion $\Delta H_{f}$ Figure $14 \mathrm{c}$ and Table 5 and this is because the functional groups of the BSA protein have no opportunity to form hydrogen bonding with functional groups of the hydrogel because recently mentioned groups are engaged with SHMP anions.

\subsubsection{Loading Procedure of Hydrogels with BSA Protein}

In order to reach maximum loading and to increase its efficiency, different loading conditions are considered. The $\mathrm{pH}$ of the loading medium, its time and the BSA concentrations were depended for loading. The UV-Visible technique at $\lambda_{\max } 279 \mathrm{~nm}$ were depended for measuring the absorbance A of BSA loaded protein on prepared hydrogels and Equations (3 and 4) are considered for determination of maximum loading percentage $\left(\% \mathrm{~L}_{\max }\right)$ and the efficiency loading percentage $(\% \mathrm{EL})$.

However, loading on hydrogel depends mainly on its degree of swelling [41]. Accordingly, and because degree of swelling is affected significantly with $\mathrm{pH}$, the loading on hydrogels was studied in different $\mathrm{pH}$ loading medium and Figure 15a has shown the efficiency of BSA loading (EL) versus different $\mathrm{pH}$ solutions in order to reach the maximum efficient loading. 

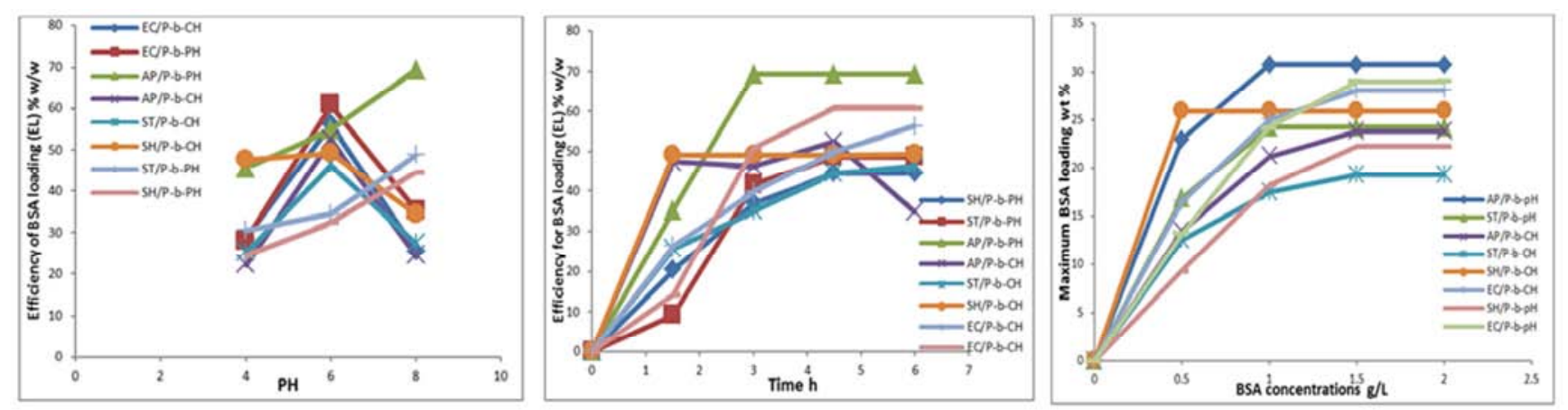

Figure 15. Efficiency of BSA loading for $a$ - $p H, b$ - Time and for c-BSA concentrations optimization.

The degree of swelling also has been found depending on time of loading, which is in the end will effect on efficiency of loading [42]. Therefore the time of loading Figure 15b also has shown a significant effect on efficiency of loading of BSA on different hydrogels.

Finally, Different BSA concentrations have been investigated in the loading of the studied hydrogels in order to achieve maximum loading percentages. Therefore, Figure $15 \mathrm{c}$ has shown the effect of different BSA concentrations on the maximum loading of BSA in order to optimize the economical concentration of BSA used for loading. The degree of swelling of the hydrogels cross-linked chemically or physically is shows significant effect on maximum loading [43]. But because the physically cross-linked hydrogels have ionic interactions between their chains, they show more effects in previous studied loading conditions than those cross linked chemically.

\subsection{BSA Releasing Investigations from Hydrogels}

Cumulative release $\left(\mathrm{R}_{\text {cum }}\right)$ percentages of BSA from different loaded hydrogels were examined and for continued $12 \mathrm{hrs}$ and for each time intervals of $3 \mathrm{hrs}$. Physiological saline (PS) solution of $0.9 \% \mathrm{w} / v$ was used as release medium because BSA hardly diffuse in D. W., Whereas the Saline ions prevent non-ionic interaction by ordering the structure of water [44] So that the BSA protein molecules absorbed on hydrophobic groups of the hydrogel could release easily in saline solution [45-47].

The release process was examined under two variable release medium conditions, where the release medium was fixed at temperatures of 15,25 and $40^{\circ} \mathrm{C}$ and its $\mathrm{PH}$ was fixed at pH4, pH6 and pH8. The Equation 5 has been depended for calculations of cumulative release $\left(R_{\text {cum }}\right)$ percentages of BSA, and new calibration curve using UVVisible spectrophotometer was prepared in PS solution for the calculation of unknown BSA concentrations released.

The degree of swelling of the hydrogels will also effects on its degree of release but because its release was in PS and not in distilled water therefore they have been shows less degree of swelling in saline solution [48].

The chemically cross linked hydrogels have shown total different behaviors in their cumulative release percentages $\left(\% \mathrm{R}_{\text {cum }}\right)$ beside the release conditions in comparison with the physically cross linked hydrogels.
Table 6. Maximum cumulative release wt of BSA from different blend hydrogels with optimize release conditions of $\mathrm{pH}$ and time.

\begin{tabular}{lllll}
\hline $\begin{array}{l}\text { Examined } \\
\text { sample }\end{array}$ & $\begin{array}{l}\text { Maximum } \\
\text { BSA loading } \\
\mathbf{w t} \%\end{array}$ & $\mathbf{p H}$ & $\begin{array}{l}\text { Temperature } \\
\left({ }^{\mathbf{}} \mathbf{C}\right)\end{array}$ & $\begin{array}{l}\text { Maximum } \\
\text { Cumulative } \\
\text { Release wt\% }\end{array}$ \\
\hline AP/P-b-CH & 23.8 & 6 & 40 & 19.6 \\
AP/P-b-PH & 30.8 & 8 & 15 & 27.2 \\
ST/P-b-CH & 19.3 & 6 & 25 & 16.2 \\
ST/P-b-PH & 24.3 & 8 & 25 & 19.6 \\
SH/P-b-CH & 25.9 & 6 & 15 & 20.7 \\
SH/P-b-PH & 22.3 & 8 & 25 & 19.4 \\
EC/P-b-CH & 28.1 & 6 & 25 & 21.4 \\
EC/P-b-PH & 29.0 & 8 & 25 & 26.6 \\
\hline
\end{tabular}

Therefore, AP/P-b-CH, ST/P-b-CH, SH/P-b-CH and EC/Pb- $\mathrm{CH}$ hydrogel have shown Figure 16 and Table 6, almost both maximum loading and maximum cumulative release of BSA except SH/P-b-CH hydrogel lower than physically cross linked hydrogels, beside showing their maximum release in neutral release medium of $\mathrm{pH} 6$ and need almost high temperature for release because the hydrogels and according to their morphological structures, their surface appear salient with a lot of folds and holes Figure 12 which help BSA to remain loaded inside the hydrogels.

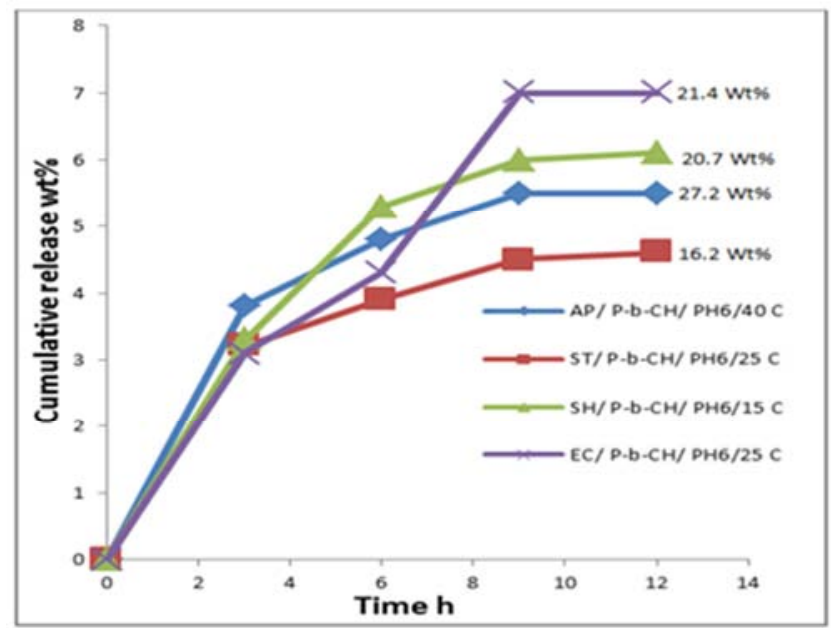

Figure 16. Maximum cumulative release of BSA from different chemically cross linked hydrogels. 


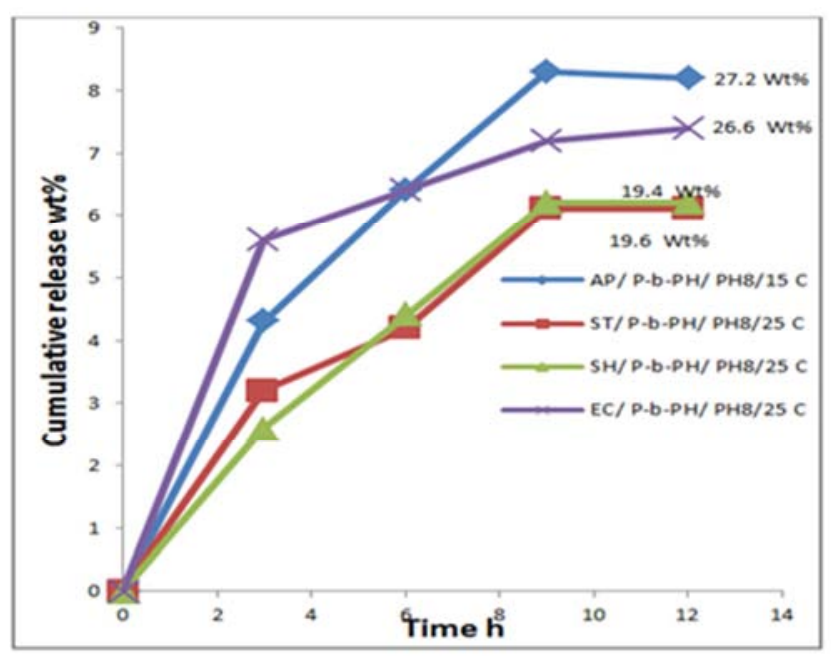

Figure 17. Maximum cumulative release of BSA from different physically cross linked hydrogels.

Whereas, the physically cross linked hyrogels have shown Figure 17 and Table 6, almost both maximum loading and maximum cumulative release of BSA higher except SH/P-b$\mathrm{CH}$ hydrogel in comparison with physically cross linked hydrogels, beside showing their maximum release in basic release medium of $\mathrm{pH} 8$ and need almost lower temperature because of the ionic interactions in physically cross linked hydrogels represented with SHMP anions and PS release medium anions which help for more repulsions between the hydrogel chains and increase the opportunity of the burst release and especially if those hydrogels are showing smooth and uniform surface with high number of pores and salience Figure 13 which could help also for more loading Figure 17 and Table 6.

The hydrogels and after release their loaded BSA should be characterized by SEM technique in order to evaluation used again as carrier for biomaterials. Therefore, studies the structures of the hydrogels after release and keep their form compact and retains with folds, holes and porosity are important signals to keep use again. The morphological surface of some studied hydrogels after release Figure 18 have shows polymers agglomerates distributed on the hydrogel surface represent cavities or holes are opened, empty and remained stable after release.
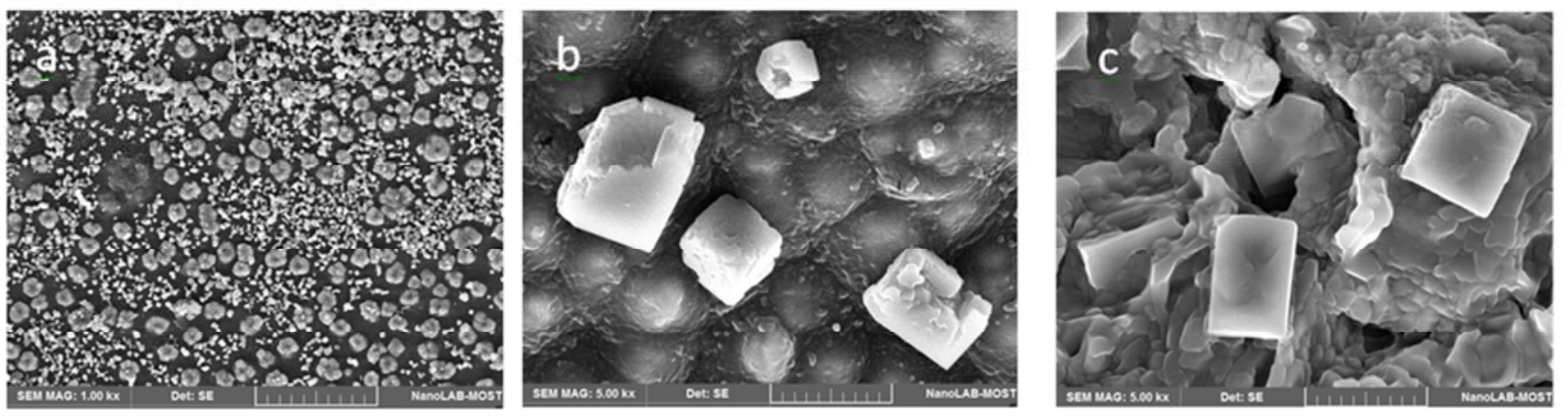

Figure 18. SEM image of $a-A P / P-b-C H, b-S T / P-b-C H, c-S H / P-b-P H$ hydrogels after release.

Moreover, the hydrogel after release remain intact and there are some salt crystals belong to the PS solution Figure 18 need remove by washing with water, then the hydrogel could be used for carrying biomaterials many times.

\section{Conclusion}

PVA blend natural polymers such as AP, ST, SH and EC could produce hydrogels have shown homogeneous blends, compact form with elastic nature and could swell easily and to high extent in water and physical saline solution. Moreover, their structures contain folds, holes with undulant and coarse surfaces that could help for loading biomaterials and then release in high efficiency. The blend hydrogels were cross linked for improve their three dimensional structures, glutaraldehyde GLU and SHMP salt have been used as chemical and physical cross linker respectively. Their natures after cross linking have shows different character according to the types of cross linker due to the ionic nature of the prepared hydrogels. Generally, all the equipments used for diagnosing, such as FTIR, XRD, DTA and SEM have shows the hydrogels are not similar either because of the types of blend natural polymer used or due to the types of the applied cross linker.

Bovine serum albumin was used as model protein for loading on different blend hydrogels. Different maximum loading percentages $\% \mathrm{~L}_{\max }$ have been recorded on different prepared hydrogels depending on the ionic nature of the hydrogels and their surface morphology beside the effects of loading conditions as $\mathrm{pH}$, time and BSA concentrations of the loading medium. The release pattern of the loaded BSA from different hydrogels has been investigated in different $\mathrm{pH}$ release solution and at different temperatures. High cumulative release percentages of BSA from different hydrogels were recorded and in different competencies according to their degree of swelling which in turn affected by both natures of the hydrogels and release conditions. Generally, all the examined hydrogels are suitable and with great efficiency could carry the BSA protein safely with no mutants. 


\section{References}

[1] Ma, S.; Yu, B.; Pei, X. and Zhou, F. "Structural Hydrogels" Polym., 98, 2016, 516-535. doi: 10.1016/j.polymer.2016.06.053.

[2] Shetye, S. P.; Godbole, A.; Bhilegaokar, S. and Gajare, P. "Hydrogels: Introduction, Preparation, characterization and Applications" Human Journals, 1 (1), 2015, 47-71.

[3] Garg, S. and Garg, A. "Hydrogel: Classification, Properties, Preparation and Technical Features" Asian Journal of Biomaterial Research; 2 (6), 2016, 163-170.

[4] Ahmed, E. M. "Hydrogel: Preparation, Characterization, and Applications: A review" J. Advan. Res., 6, 2015, 105-121. doi: 10.1016/j.jare.2013.07.006.

[5] Saini, K. "Preparation Method, Properties and Crosslinking of Hydrogel: A review" Magazine. Pharmatutor. Org., 5 (1), 2017, 27-36.

[6] Mallikarjuna, C.; Bhaskar, V. H.; Kumar, J. M.; Mounica, R. and Bolla, S. P. "Hydrogel-A Novel Carrier" PharmaTutor, 2 (6), 2014, 42-51. doi: 10.5923/j.ajps.20140402.01.

[7] Datta, A. "Characterization of Polyethylene Glycol Hydrogels for Biomedical Applications" M.Sc. Thesis, B. E. University of Pune, India, 2007.

[8] Baker, M. I.; Walsh, S. P.; Schwartz, Z. and Boyan, B. D. "A review of Polyvinyl Alcohol and Its Uses in Cartilage and Orthopedic Applications" J. Biom. Mat. Res. B, 9999B, 2012, 1-7. doi: $10.1002 / \mathrm{jbm} . b .32694$.

[9] Stasko, J.; Kalniņš, M.; Dzene, A. and Tupureina, V. "Poly (vinyl alcohol) Hydrogels" Proceed. Estonian Acad. Scien., 58 (1), 2009, 63-66. doi: 10.3176/proc.2009.1.11.

[10] Gomez, F. M.; Guerrero, J.; Matsuhiro, B. and Pavez, J. "In Vitro Release of Metformin Hydrochloride from sodium Alginate/ Polyvinyl alcohol Hydrogels" Carbohy. Polym. 155, 2017, 182-191. doi: 10.1016/j.carbpol.2016.08.079.

[11] Silva, F. E. F.; Di-Medeiros, M. C. B.; Batista, K. A. and Fernandes, K. F. "PVA/Polysaccharides Blended Films: Mechanical Properties" J. Mater., 2013, 2013, 6. doi: $10.1155 / 2013 / 413578$.

[12] Marin, E.; Rojas, J. and Ciro, Y. "A review of Poly vinyl alcohol Derivatives: Promising Materials for Pharmaceutical and Biomedical Applications" African J. Pharm. Pharmacol., 8 (24), 2014, 674-684. doi: 10.5897/AJPP2013.3906.

[13] Jane, J-L. and Chen, J.-F. "Effects of Amylose and Amylopectin on the Functional Properties of Starch", M. SC. Thesis, Cereal Chem., 69 (1), 1992, 60-65.

[14] Lawal, O. S.; Adebowale, K. O. and Oderinde, R. A. "Functional Properties of Amylopectin and Amylose Fractions Isolated from Bambarra Groundnut (Voandzeia Subterranean) Starch" African J. Biotech., 3 (8), 2004, 399-404. doi: 10.5897/AJB2004.000-2082.

[15] Patel, A. R.; Remijn, C.; Cabero, A. M.; Heussen, P. C. M.; Hoorn, J. W. M. S. and Velikov, K. P. "Novel All-Natural Microcapsules from Gelatin and Shellac for Biorelated Applications" Adv. Funct. Mater, 23, 2013, 4710-4718. doi: 10.1002/adfm.201300320.
[16] Sharma, K.; Singh, V. and Arora, A. "Natural Biodegradable Polymers as Matrices in Transdermal Drug Delivery" Int. J. Drug Dev. \& Res., 3 (2), 2011, 85-103.

[17] Chauhan, O. P.; Nanjappa, C.; Ashok, N.; Ravi, N.; Roopa, N. and Raju, P. S. "Shellac and Aloe vera Gel Based Surface Coating for Shelf Life Extension of Tomatoes" J. Food Sci. Tech., 52 (2), 2015, 1200-1205. doi: 10.1007/s13197-0131035-6.

[18] Bertoft, E. "Understanding Starch Structure: Recent Progress" Agronomy, 7, 2017, 56. doi: 10.3390/agronomy7030056.

[19] Pal, K.; Banthia, A. K. and Majumdar, D. K. "Preparation of Transparent Starch Based Hydrogel Membrane with Potential Application as Wound Dressing" Trends Biomater. Artif. Organs, 20 (1), 2006, 59-67.

[20] Khan, S. A.; Ahmad, M.; Aamir, M. N.; Murtaza, G.; Rasool, F. and Akhtar, M. "Study of Nimesulide Release From Ethylcellulose Microparticles and Drug-Polymer Compatibility Analysis" Lat. Am. J. Pharm., 29 (4), 2010, 554-61.

[21] Hegyesi, D. "Study of the Widely Used Ethylcellulose Polymer as Film Forming and Matrix Former Agent" Ph. D Thesis, Szeged University, Hungary, 2016.

[22] Wang, T.; Gunasekaran, S., "State of Water in Chitosan-PVA Hydrogel" J. Appl. Polym. Sci., 101, 2006, 3227-3232. doi: 10.1002/app.23526.

[23] Sing, B.; Sharma, D. K.; Gupta, A., "In Vitro Release Dynamics of Thiram Fungicide from starch and Ploy (methacrylic acid)-based Hydrogeles" J. Haz. Mat., 154, 2008, 278-286. doi: 10.1016/j.jhazmat.2007.10.024.

[24] Krishna Rao, K. S. V.; Kiran Kumar, A. B. V.; Madhusudhan Rao, K.; Subha, M. C. S.; Lee, Y., "Semi-IPN hydrogels based on Poly (vinyl alcohol) for controlled release studies of chemotherapeutic agent and their Swelling characteristics", Polym. Bullet., 61, 2008, 81-90. doi: 10.1007/s00289-0080925-7.

[25] Saputra, A. H.; Qadhayna, L.; Pitaloka, A. B., "Synthesis and Characterization of Carboxymethyl cellulose (CMC) from Water Hyacinth Using Ethanol-Isobutyl Alcohol Mixture as the Solvents" Int. J. Chem. Eng. Appl., 5 (1), 2014, 36-40. doi: 10.12988/ces.2015.511300.

[26] Maitra, J. and Shukla, V. K., "Cross-linking in Hydrogels" Amer. J. Polym. Sci., 4 (2), 2014, 25-31. doi: 10.5923/j.ajps.20140402.01.

[27] Gupta, K. C. and Jabrail, F. H., "Preparation and characterization of sodium hexameta phosphate cross-linked chitosan microspheres for controlled and sustained delivery of centchroman"Inter. J. Biol. Macro., 38, 2006, 272-283. doi: 10.1016/j.ijbiomac.2006.03.013.

[28] Salmawi, K. M., "Application of poly (vinyl alcohol) (PVA)/Carboxy methyl cellulose (CMC) Hydrogel produced by conventional cross-linking or by freezing and thawing" J. Macro. Sci. part A Pure Appl. Chem., 44 (6), 2007, 619-624. doi: 10.1080/10601320701285045.

[29] El- Rafaie, K. and El- Meligy, M. A. "Physically Crosslinked Poly (vinyl ahcohol)- Hydroxyethyl starch blend Hydrogel Mcmbranes: Synthesis and Characterization for Biomedis Applications" Arab. J. Chem., 7 (3), 2014, 372-380. 
[30] Mittal, A.; Garg, S.; Kohli, D.; maiti, M.; Jana, A. K. and Bajpai, S, "Effect of cross-linking of PVA/starch and reinforcement of Modified Barley Husk on the properties of composite Films". Carbohy. Polym. 151, 2016, 926-938. doi: 10.1016/j.carbpol.2016.06.037.

[31] Chen, D.; Amstad, E.; Zhao, C-X.; Cai, L., Fan, J.; Chen, Q,; Hai, M., Koehler, S.; Zhang, H.; Liang, F.; Yang, Z. and Weitz F. "Biocompatible Amphiphilic Hydrogel- Solid Dimer Particles as Colloidal Surfactants" ACS Nano, 11 (12), 2017, 11978-11985. doi: 10.1021/acsnano.7b03110.

[32] Tovar C. K. T; Tamayo, G.; Donohue, A.; Kobayaashi, T. aand Saucedo, A. R. A., "Obtaining of Hydrogels Using PVA and HEC for Adipose Tissue Regeneration', J. Tiss. Sci. Eng., 6 (2), 2015, 152-156. doi: 10.4172/2157-7552.1000152.

[33] Deshpande, D. S.; Bajpai, R.; Banjpai, A. K., "Synthesis and Characterization of Acrylonitrile Incorporated PVA Based Semi-inter Penetrating Polymeric Networks" Int. J. Chem. Res., 3 (3), 2011, 74-82. http://www.bioinfo.in/contents.php?id=23.

[34] Jabrail, F. H and Mahmood, E. M., "Hydrophilic Monomers Graft Gum Arabic Hydrogels Prepared in Different Crosslinking Nature and Study of their Effects on Irrigation of Agriculture Soil" Rec. J. Chem. Sci., 6 (1), 2016, 1-19.

[35] Mahmood, E. M., "Preparation and Characterization of Superabsorbent Polymers and Study of their Effects on Agriculture Soil" MSc. Thesis, Mosul university, Iraq, 2015.

[36] El- Naggar, A. W. M.; Senna, M. M.; Mostafa, T. A; Helal, R. H, "Radiation Synthesis and Drug Delivery Prpperties of Interpentrating Networks (IPNS) Based on (Vinyl alcohol)/methyl cellulose Blend Hydrogels" Int. J. Bio. Macro., 102, 2017, 1045-1051. Joi: 10.1016/j.ijbiomac.2017.04.084.

[37] Fan, L.; Yang, H.; Yang, J.; Peng, M.; hu, J., "Preparation and characterization of chitosan/ Gelatin/ PVA Hydrogel for Wound Dressinfs" Carbohy. Polym., 146, 2016, 427-434. doi: 10.1016/j.carbpol.2016.03.002.

[38] Akhtar, M. F.; Ranjha, N. M., "Methods of Synthesis of Hydrogels" Saudi Pharm J., 24 (5), 2016, 554-559. doi: 10.1016/j.jsps.2015.03.022.

[39] Pourjavadi, A.; Amini- Fazl, M. S.; Ayyari, M., "Optimization of Synthetic Conditions CMC-g-poly (acrylic acid)/ Celite Composite Superabsorbent by Taguchi Method and determination of its Absorbency Under load" Exp. Poly. Let. 1 (8), 2007, 488-494. doi: 10.3144/expresspolymlett.2007.69.

[40] Chen, J.; Park, H. and Park, K., "Synthesis of Superporous Hydrogels: Hydrogel with Fast Swelling and Superabsorbent Properties" J. Biomed. Mater. Res., 44 1999, 53-62. doi: 10.1002/(SICI)1097-4636(199901)44:1<53:AID-JBM6>3.0. $\mathrm{CO} ; 2-\mathrm{W}$.

[41] Rizwan, M.; Yahya, R.; Hassan, A.; Yar, M.; Azzahari, A. D.; Selvanathan, V.; Sonsudin, F.; Abouloula, C. N., "PH Sensitive Hydrogels in Drug Delivery: Brief History, Properties, Swelling and Release Mechanism, Material Selection and Application" Poly. 9, 2017, 137-173. doi: 10.3390/polym9040137.

[42] Sriamornsak, p.; Nunthanid, J.; Cheewatanakornkornkool, K.; Manchun, S.,"Effect of Drug Loading Method on Drug Content and Drug Release from calcium pectinate gel beads" AAPS pharm. Sci. Tech., 11 (3), 2010, 1315-1319. doi: 10.1208/s12249-010-9513-x.

[43] Parhi, R., "Cross-linked Hydrogel for Pharmaceutical Applications: A Review" Adv. Pharm. Bull., 7 (4), 2017, 515 530. doi: 10.15171/apb.2017.064.

[44] Rose, S., "Protien Purification Methods a Practical Approach", Harris Elv, Angal $2^{\text {nd }}$ (ed), IRL Press, New York, 1989.

[45] Oztop, H. N.; Saraydin, D.; Solpan, D.; Giiven, O., "Adsorption of BSA onto Radiation-crosslinked Poly (AAm/HPMA/MA) Terpolymers", Polym. Bull., 50, 2003, 183-190. doi: 10.1007/s00289-003-0152-1\}.

[46] Wang, Y.; He, G.; Li, Z.; Hua, J.; Wu, M.; Gong, J.; Zhang, J.; Ban, L.; Huang, L.,"Novel Biological Hydrogel: Swelling Behaviors Study in Salt Solutions with Different Ionic Valence Number", Polymers, 10, 2018, 112-124. doi: 10.3390/polym10020112.

[47] Asenjo, J. A.; Andrews, B. S., "Aqueous two-phase systems for protein separation: A perspective", J. of Chromat. A, 1218, 2011, 8826-8835. doi: 10.1016/j.chroma.2011.06.051.

[48] Hosseinzadeh, H., "Synthesis and Swelling Properties of a Poly (vinyl alcohol)-Based Superabsorbing Hydrogel", Curr. Chem. Lett., 2, 2013, 153-158. doi: 10.5267/j.ccl.2013.05.001. 